\title{
4 Judenfeindliche Stereotype und ihre historische Verankerung
}

\subsection{Zur Genese des Ressentiments: Warum die Juden?}

\begin{abstract}
„Ein solch verzweifeltes, durchböstes, durchgiftetes, durchteufeltes Ding ist's um diese Juden, so diese 1400 Jahre unser Plage, Pestilenz und alles Unglück gewesen sind und noch sind. Summa, wir haben rechte Teufel an ihnen. Das ist nichts anderes. Da ist kein menschliches Herz gegen uns [...]. Solches lernen sie von ihren Rabbinern in den Teufelsnestern ihrer Schulen.“1 (Luther [1543] 1577: 371 f.)
\end{abstract}

„Ich nenne dieses Fremde schon an sich eine Plage und ein Verderben. Es ist noch mehr so zu nennen, weil die Juden ein verdorbenes und entartetes Volk sind.“ (Arndt 1814: 193)

Um verstehen zu können, wie tief verwurzelt die kognitiven Stereotype und die emotionalen Ressentiments gegenüber Juden sind, muss man sich deren lange Geschichte anschauen. Die Sprachgebrauchsmuster der historischen und der zeitgenössischen Judenfeindschaft ähneln sich sowohl von ihrer Semantik als auch ihrer Form her frappierend. Vielen Menschen ist aber nicht bekannt bzw. bewusst, dass die aktuell kursierenden, negativ be- bzw. entwertenden verbalen Charakterisierungen von Juden und/oder Israelis zum Teil seit Jahrhunderten zum Standardrepertoire von Antisemiten gehören. Dementsprechend fehlt auch oft das kritische Bewusstsein für die Brisanz bestimmter Äußerungen. Die aktuellen Formen des Verbal-Antisemitismus lassen sich nur über die Kenntnis der tradierten Konzeptualisierungstypen und der Sprachgebrauchsmuster von Judenfeindschaft als solche beschreiben und angemessen erklären. Die relevanten Stereotype, die zum Teil seit Jahrhunderten existieren und über Sprache sowie Bilder bis zum heutigen Tag kodiert werden, sollen daher im Folgenden kurz skizziert $^{2}$ und in ihrem historischen Kontext ${ }^{3}$ erörtert werden, um die ungebrochene Kontinuität des judenfeindlichen Gedankengutes aufzuzeigen.

\footnotetext{
$1 \mathrm{Im}$ Original: „Ein solch verzweiffelt / durchböset / durchgifftet / durchteuffelt ding ists vm diese Jüden / so diese 1400. Jar vnser plage / Pestilenz vnd alles unglück gewest / vnd noch sind. Summa wir haben rechte Teuffel an ihnen / das ist nichts anders / Da ist kein Menschlich Herz gegen vns Heyden / Solchs lernen sie von ihren Rabinen in den Teuffels Nestern ihrer Schulen.“ (Luther [1543] 1577: 371 f.)

2 Ausführliche Abhandlungen zu den meisten, hier nur knapp erörterten Stereotypen finden sich in Schoeps/Schlör (1999). Zu grundlegenden Ausführungen s. auch Katz (1980), Almog (1988), Wistrich (1991), Klamper (1995), Laqueur (2006).
}

3 Wir verzichten aber auf ausführliche Beschreibungen und Erklärungen sowie den Abriss einer 
Das Phänomen der Judenfeindschaft und des Judenhasses zeigt sich seit zwei Jahrtausenden verbal und nonverbal in den Formen der Diskriminierung, Einschüchterung, Verfolgung, Erniedrigung und Ermordung von Juden und involviert als komplexes Phänomen religiöse, historische, ökonomische, politische, psychologische, kommunikative und philosophische Aspekte (vgl. Bauer 1985 und 1992, Reinharz 1987, Wistrich 1990 und 2010, Bergmann 32006, Laqueur 2006, Nonn 2008). Allen Typen und Ausprägungsvarianten der Judenfeindseligkeit liegen jedoch zeitlos spezifische Konzeptualisierungsmuster zugrunde, die als mentale Konstrukte die Vorstellungen von Nicht-Juden über Juden repräsentieren. Wandelten sich im Laufe der Geschichte auch immer wieder die Erscheinungs- und Ausdrucksformen der judeophoben Antipathie und Ablehnung, so blieb doch als verbindendes Element stets das konzeptuell und emotional tief verankerte Ressentiment gegenüber Juden bestehen, unabhängig von den jeweils aktuellen politischen, ökonomischen, sozialen und/oder ideologischen Motiven, Begleiterscheinungen und Einflussgrößen (vgl. auch Grammel 2002: 9).

Warum aber die Juden? Warum wurden von allen Gemeinschaften und Gruppen in der Welt über die Jahrhunderte hinweg besonders die Juden mit Hass und Gewalt verfolgt, warum wurde jedes Unglück, jede Seuche, jede Missetat ihnen zugesprochen (s. hierzu auch Prager/Telushkin 2003)? Warum mündete diese Feindseligkeit schließlich in der radikalen Ausrottungspolitik der Nationalsozialisten? Und warum hält sich bis zum heutigen Tage moderner Antisemitismus auch in gebildeten Kreisen ${ }^{4}$ - trotz der Erfahrung Auschwitz und trotz aller Aufklärung? Diese viel und intensiv diskutierten Fragen (die von Judenfeinden stets mit dem Verweis auf Charakter und Taten der Juden selbst beantwortet wurden und werden; s. Kap. 5.2) lassen sich nur beantworten, wenn man sich klarmacht, dass Judenfeindschaft kein Vorurteilssystem unter vielen, sondern aufgrund seiner Verwurzelung in ein moralisches und konzeptuelles Weltdeutungssystem, das so bei keiner anderen Form der gruppenorientierten Menschenfeindschaft existiert, unikal ist. Judenhass bedeutet nicht nur Hass auf das spezifisch Andere, das eigentümliche Fremde, sondern auf das (vermeintlich) ultimative Böse in der

lückenlosen Chronologie. Für unser Anliegen ist es wichtig aufzuzeigen, dass die Stereotype, die in der aktuellen Kommunikation zu beobachten sind, eine lange Tradition haben und als Teil des kulturellen Wissens zu betrachten sind, das teils bewusst, teils unbewusst und völlig unreflektiert über die Sprache vermittelt wird. Wir konzentrieren uns daher auf einige ausgewählte Beispieltexte aus den vergangenen fünf Jahrhunderten und zeigen insbesondere anhand von Texten des 19. Jahrhunderts, wie weit verbreitet und habitualisiert homogen negative Konzeptualisierungen über Juden in allen Gesellschaftskreisen waren.

4 Umfragen und Untersuchungen aus dem Jahr 2011 zufolge haben 20 Prozent der Deutschen antisemitische Ressentiments und glauben an entsprechende Klischees (s. BMI 2011). S. hierzu auch Schwarz-Friesel et al. (2010). 
Welt. Die Genese dieser gegen die Existenz der Juden gerichteten Weltdeutung liegt in der Abspaltung von Juden- und Christentum.

Das älteste, bereits in der Antike $e^{5}$ entstandene Stereotyp über Juden ist das der JUDEN ALS FREMDE.

Drei Jahrhunderte vor der christlichen Zeitrechnung fanden in Alexandria schon Übergriffe gegen Juden statt. Der griechische und römische Anti-Judaismus der vorchristlichen Zeit basierte maßgeblich auf der Vorstellung von Juden als „den Fremden“ (Horkheimer [1946] 2002: 30, Grunberger 1962: 265, Grunberger/ Dessuant 2000: 264, Wistrich 2010: 81). Diese (nicht nur auf generellen xenophoben Tendenzen basierende, sondern spezifisch auf die Gemeinschaft der Juden bezogene) Konzeptualisierung ${ }^{6}$ fand in griechischen Schriften ${ }^{7}$ ihren Ausdruck und fungierte über die Jahrhunderte hinweg als ein Basis-Stereotyp, das der $\mathrm{Ab}$ - und Ausgrenzung von Juden diente und in diversen Abwandlungen kontinuierlich erhalten blieb. Das Konzept des ANDEREN und FREMDEN entwickelte sich aber erst nach der Spaltung von Judentum und Christentum in Verbindung mit den religiös motivierten Hassgefühlen zu einer genuin judenfeindlichen Konzeptualisierung (JUDEN ALS VERWEIGERER DES WAHREN GLAUBENS, ${ }^{8}$ JUDEN

\footnotetext{
5 Judenfeindschaft entstand erstmals nach dem Jahr 500 vor Christus durch die diversen Auswanderungen von Juden ins Exil, bedingt durch die Zerstörung des ersten Tempels. Als deutlich von anderen Gruppen abgegrenzte Minderheit (die sich in Ess-, Kleidungs-, Wohnund Sabbatkultur unterschied), die sich der Assimilation an das Gastland entzog, erhielten die Juden bereits in der Antike viel Aufmerksamkeit, die zu Bewunderung (und Übertritten zum Judaismus), aber auch viel Ablehnung führte. Praktiziertes Judentum wurde bereits im antiken Rom als Provokation erachtet. Bereits in dieser frühen Phase entstand die aus Furcht und Argwohn genährte Vorstellung von der Unterhöhlung der bestehenden Gesellschaften und weiterreichend die Sorge bezüglich der Weltübernahme durch die Juden (s. Heinemann 1931 und mündliche Mitteilung von Moshe David Herr).
}

6 Es waren zwei für die jüdische Gemeinschaft zentrale Eigenschaften, die bereits in der Antike als negativ bewertende Abgrenzungsmerkmale von Griechen, Römern und Ägyptern gesehen wurden: zum einen der monotheistische Glaube an einen unsichtbaren Gott und zum anderen die Selbstattribuierung, ein auserwähltes Volk zu sein. Beides wurde von den benachbarten Völkern als seltsam, als unnormal empfunden. Die hartnäckige Weigerung, die Götter der anderen Glaubensgemeinschaften anzuerkennen, wurde als starrsinnig und überheblich angesehen (vgl. Heinemann 1931). Xenophobe Tendenzen waren allerdings in der Antike auch gegen andere Minoritäten zu beobachten. Der tiefe, alle Lebensdimensionen erfassende Hass gegenüber Juden entstand erst nach der Abspaltung des Christentums vom Judentum.

7 S. Heinemann (1931) und Herr (1988).

8 Durch Marcion kam es im zweiten Jahrhundert nach christlicher Zeitrechnung zu der Forderung, Christentum und Judentum strikt voneinander abzugrenzen. In seiner Theologie wird der „gute Gott“, wie er von Jesus verkündigt wurde, von einem „bösen Gott“ der Juden unterschieden. Das Judentum wird als überholte Religion betrachtet, die keine 
ALS CHRISTUSMÖRDER, ${ }^{9}$ JUDEN ALS DAS ABSOLUT BÖSE). Hier liegt der Ursprung des seit zweitausend Jahren andauernden Judenhasses. Die Urchristen, eine jüdische Gruppe, die sich zu Anfang allein durch den Glauben an Jesus als den Messias von den anderen Juden unterschied, vollzogen zunehmend eine die Differenzen betonende Abgrenzung vom Judentum. Nicht Jesus und seine Jünger, sondern Paulus führte die Spaltung herbei: Nur wer an Jesus als Erlöser glaube, sei ein Vertreter des wahren Glaubens. Allein dieser Glaube sei entscheidend für ein wahres Judentum und nicht mehr die Einhaltung der tradierten Regeln des Judentums. Verdammt sei, wer diesen Glauben nicht annehme. In den theologischen Schriften von Paulus wurde die Basis für die strikte Abgrenzung von Juden, den Glaubensverweigerern, und Christen, den einzigen wahren Glaubenden gelegt. Drastisch ausformuliert fand diese Dichotomie im Evangelium des Johannes ihren Ausdruck: Dort wurde die Dämonisierung und Verdammung der Juden als Ungläubige vollzogen. Zudem wurde durch die Darstellung, Jesus sei durch Juden und jüdisches Gesetz umgebracht worden (was angesichts der realen politischen Lage des durch die Römer besetzten und mit absoluter Herrschaft regierten Landes historisch völlig unplausibel war; s. hierzu Cohen 1977), das Stereotyp der Gottesmörder etabliert (s. hierzu u. a. Parkes 1981, Simon 1996, Laqueur 2006, Wistrich 2010). Das Fundament der Konzeptualisierung des wahren und des falschen (teuflischen) Israel wurde so gelegt.

Die radikale Abspaltung von der Ursprungsreligion und ihre fundamentale Ablehnung basierten u.a. auf der Enttäuschung über die Uneinsichtigkeit der jüdischen Mitbürger: dass Jesus, der Jude, ausgerechnet von den Juden, aus deren Mitte er kam, nicht als Messias, nicht als der Erlöser anerkannt wurde. Aus

Existenzberechtigung mehr hat (vgl. Parkes 1981, Rokeah 1988). Bei Justin findet sich die Aussage, die Christen und nicht die Juden seien das „wahre Israel“ (,Verus Israel“). Besonders einflussreich und für viele Jahrhunderte prägend für das Verhältnis der christlichen Kirche zu den Juden waren die Schriften von Augustinus im fünften Jahrhundert (s. De Civitate Dei). Er unterscheidet „Israel im Geiste“ (die Christen) und „Israel im Fleische“ (die Juden). Juden sind ihm zufolge Sünder, da sie den wahren Glauben leugnen, aber als Zeugen der wahren Geschichte von Jesus (bis sie den wahren Glauben übernehmen) müssen sie (mit Verachtung) geduldet werden. Diese Duldung (bis zur Einsicht und Akzeptanz des wahren Glaubens) beinhaltete das Verbot, Juden zu töten (s. Simon 1996). Dass die „sündigen, verachtenswerten Ungläubigen“ gemäß der augustinischen Kirchendoktrin nicht einfach umgebracht werden durften, war ein weiterer Grund für den Zorn und die ohnmächtige Wut von Nicht-Juden und somit Fundament für Ressentiments.

9 Die Gottesmordbeschuldigung (als Topos der jüdischen Kollektivschuld am Tode von Jesus) findet ihre Verbreitung ab dem zweiten Jahrhundert nach Christus. Erst durch das zweite vatikanische Konzil 1965 löste sich die Kirche offiziell von dieser Legende. Fanatische Christenverbände erkennen diesen Beschluss bis heute nicht an (z. B. die Piusbrüder). S. hierzu auch Grözinger (1999). 
dieser Enttäuschung kam der Groll, der das emotionale Fundament des frühen anti-judaistischen Ressentiments ${ }^{10}$ legte. Die Verabsolutierung der eingenommenen Glaubensposition erlaubte kein Zugeständnis an die Möglichkeit der eigenen Fehlbarkeit: Die Akzeptanz der Juden und ihres Glaubens hätte bedeutet, den Zweifel am eigenen Glauben zumindest hypothetisch, als kognitive Möglichkeit zuzulassen, denn die prinzipielle Berechtigung der Existenz jüdischen Lebens umfasste die Möglichkeit, Jesus unter Umständen nicht als Gottes Sohn zu sehen. Dieser prinzipielle Zweifel jedoch musste unter allen Umständen verhindert werden. Die Juden wurden somit zum Gegenentwurf der eigenen Existenz, zum ultimativ Anderen, das als das Böse, Schlechte entwertet werden und damit außerhalb aller gültigen Werte stehen musste.

Die Entstehung und Ausbreitung des Christentums als umfassende Weltreligion geht einher mit der Entwicklung der Feindschaft gegenüber Juden, ihrer Stigmatisierung und Ausgrenzung. Das Urbild des verstockten, sich der Mehrheitsgemeinschaft widersetzenden, für sich bleibenden, auf seiner Existenz- und Glaubensform beharrenden jüdischen Menschen wurde hier aufgebaut und verfestigt. Alle weiteren (auch von der Religion losgelösten) Erscheinungsformen des Anti-Judaismus gehen letztendlich trotz aller zum Teil erheblichen Transformationen auf diese, die Welt in 'richtig und falsch' einteilende Konzeptualisierung zurück. Die lange Geschichte der Judenfeindschaft lässt sich natürlich nicht monokausal erklären, da sich die Feindschaft im Laufe von zweitausend Jahren immer wieder veränderte und den jeweiligen Dispositionen und Situationen anpasste (s. hierzu u. a. Parkes 1963, Poliakov 1985, Almog 1988, Laqueur 2006). Aber die Genese der Judeophobie liegt in der Trennung von Juden- und Christentum. Der genuine Judenhass beginnt mit dem Anspruch der Christen, insbesondere der Kirchengelehrten, den einzig wahren Glauben zu vertreten, und ist gekoppelt an den institutionellen Ausbau des Christentums als Weltreligion (vgl. Parkes 1981).

Aus der Konkurrenz zwischen dem Judentum und dem sich etablierenden Christentum, das sich seinen Platz als weltbeherrschende Religion über Jahrhunderte erkämpfen musste, ${ }^{11}$ ergab sich die Spezifik des christlichen Judenhasses.

10 Nach der klassischen Definition Max Schelers, die auch heute noch als grundlegend anzusehen ist, ist das Ressentiment „das wiederholte Durch- und Nachleben einer bestimmten emotionalen Antwortsreaktion gegen einen anderen“ (Scheler [1912] 41955: 36). Der Groll führt zur Ablehnung, zum Hass. Während sich einzelne Gefühle auf etwas Bestimmtes am Anderen (Äußeres, Handlungen etc.) richten, zielt das Ressentiment auf die Existenz des Anderen. Es ist „ein ganz allgemeiner Wertnegativismus, eine ganz unbegründet erscheinende und scheinbar regellos hervorbrechende, plötzliche haßerfüllte Ablehnung selbst" (Scheler [1912] 41955: 61). 11 Das Christentum sah sich bis in das dritte Jahrhundert nach Christus (bis zum sogenannten Mailänder Toleranzedikt) massiven Anfeindungen und Verteufelungen ausgesetzt, die es in 
Der christlichen Lehre folgend hätte mit dem Erscheinen des Messias das Judentum aufhören müssen zu existieren (vgl. Bauer 1992: 83).

Um sich als die einzige, die wahre, die unantastbare Religion etablieren zu können, musste die Ursprungsreligion komplett negiert werden. Diese Negation führte zu einem radikalen Gegenentwurf und zur Verdammnis des Judentums als Religion sowie der diesem Glauben verhaftet bleibenden Menschen. Sie legte zudem die Basis für alle weiteren, nicht-religiösen Varianten der Judenfeindseligkeit. Die Hass-Forschung (s. Haubl 2007) zeigt übereinstimmend, dass besonders tiefe Abwehrgefühle da entstehen und sich halten, wo Affinität zwischen Hassobjekt und Hasssubjekt besteht: Genau diese Affinität zeichnet das Verhältnis der jüdischen und der christlichen Religion aus.

Warum die Juden? Weil Jesus, der Verkünder der urchristlichen Lehren, ein Jude war, untrennbar verbunden mit dem Judentum, seinem Gottesglauben und seinen Gesetzen, der auf der Basis der jüdischen Religion die Grundlagen für einen neuen Zugang zum Menschsein und zu Gott legte und weil die, welche nach ihm das Christentum zur Weltreligion auf- und ausbauten, weder seine gepredigte Toleranz noch seine Botschaft von Liebe und Barmherzigkeit leben konnten oder wollten, sondern stattdessen in Wut und Hass gegenüber ihren eigenen Wurzeln verfielen, die sie in glühender Intoleran $z^{12}$ ausrotten bzw. nicht

einem Umkehrprozess gegen die Juden richtete. Der das Judentum als Religion vollständig und absolut entwertende Umkehrschluss beinhaltete auch die Festsetzung, nicht das Christentum sei etwa das Kind des Judentums, sondern das Judentum sei vielmehr eine Perversion des Christentums. Der Barnabasbrief (viertes Jahrhundert) gibt Einblick in die theologischen Auseinandersetzungen der frühen christlichen Kirche mit dem Judentum (s. Rokeah 1988). Dort werden die jüdische Lehre als „überholt“, die Juden als „unwürdig“ und „von einem bösen Engel“ beeinflusst dargestellt. Das jüdische Israel sei im „Untergang“. Diese frühe Schrift ist im Sinne der nachfolgenden Adversus-Judaeos-Texte der Kirchenväter geschrieben, d. h. sie stellen eine kategorische Ablehnung und absolute Entwertung des Judentums dar. Jüdische Figuren werden christianisiert, d. h. als frühe Vertreter des Christentums interpretiert. So wie der Jude Jesus von Nazareth aus dem Judentum gerissen wurde, so wurde auch Abraham im Barnabasbrief und nachfolgenden Texten als erster Christ stilisiert (s. hierzu auch Parkes 1981: 84). 12 Unter fundamentalistischen Christen findet sich diese Intoleranz bis heute, s. etwa die Piusbruderschaft oder die Anhänger von kreuz.net: Es ist signifikant, dass diese religiös motivierten Judenhasser zugleich auch den Holocaust leugnen bzw. marginalisieren. In der Karfreitagsfürbitte für die Juden heißt es: „Oremus et pro ludaeis ut Deus et Dominus noster illuminet corda eorum, ut agnoscant lesum Christum salvatorem omnium hominum. Oremus. Flectamus genua. Levate. Omnipotens sempiterne Deus, qui vis ut omnes homines salvi fiant et ad agnitionem veritatis veniant, concede propitius, ut plenitudine gentium in Ecclesiam Tuam intrante omnis Israel salvus fiat. Per Christum Dominum nostrum. Amen.“ (,Wir wollen beten für die Juden. Dass unser Gott und Herr ihre Herzen erleuchte, damit sie Jesus Christus erkennen, den Heiland aller Menschen. Lasset uns beten. Beugen wir die Knie. Erhebet Euch. Allmächtiger ewiger Gott, der Du willst, dass alle Menschen gerettet werden und zur Erkenntnis der Wahrheit 
akzeptieren wollten. Aus Jesus, dem Juden, wird Christus, der Heiland, von den Juden ermordet, losgelöst von seinen jüdischen Wurzeln, transformiert zu einem Wesen jenseits des Judentums; aus den ehemaligen Glaubensbrüdern werden Anti-Christen, die sich dem wahren Glauben verweigern; aus dem Judentum wird eine Verdammnis. Die Koexistenz zweier Religionen mit gemeinsamen Fundamenten kann nicht geduldet werden: Die Existenz von Juden wird zum Frevel. Aus diesem Frevel entwickelt sich die totale Entwertung alles Jüdischen. Juden werden zum Archetypus des Üblen und Verwerflichen in der Welt. Aus einer theologischen Interpretation wird im Laufe der Jahrhunderte eine allumfassende Ethik, aus religiöser Deutung und Doktrin ein Weltdeutungssystem, in dem Juden und Judentum prinzipiell als die negative Dimension entwertet werden.

Zieht man in Betracht, dass die Institution der christlichen Kirche mit ihren Lehren und dem Neuen Testament als wichtigste gesellschaftliche und ideologische Kraft über 1.800 Jahre hinweg maßgeblichen Einfluss auf alle Sphären des Lebens, alle sozialen, kulturellen und politischen Strukturen und Prozesse nahm, alle literarischen und bildenden Kunstformen dominierte, die jeweiligen Herrschaftsstrukturen begleitete oder formte (und bis heute in weiten Teilen der Gesellschaft als Faktor wirkt), ist es nicht verwunderlich, dass das von ihr etablierte und gepflegte Feindbild bzw. Gegenbild JUDE trotz aller historischen Veränderungen die Jahrhunderte überlebte. Judenfeindschaft ist eine in der abendländischen Kultur tief verwurzelte Mentalität, die Jahrhunderte hindurch von Generation zu Generation, als fester Bestandteil der christlich geprägten Tradition und Identität vermittelt wurde.

„Der Jud stellt sein sinne nacht und tag Wie er den cristen verderben mag ['kann', d. Verf.]"'

(Titel eines anonymen Flugblatts des 15. Jahrhunderts, zit. n. Hortzitz 1999: 37)

Juden sind demnach nicht ein Feind, sie sind der Feind. Neben dem metaphysischen Übel sind sie auf der Erde das ultimativ Böse, die menschliche Verkörperung des Schlechten, in der christlichen Glaubensvorstellung der Anti-Christ ${ }^{13}$

\footnotetext{
gelangen, gewähre gnädig, dass beim Eintritt der Fülle aller Völker in Deine Kirche ganz Israel gerettet wird. [oder: dass ganz Israel gerettet werde, wenn die Fülle aller Völker in Deine Kirche eintritt]. Durch Christus, unseren Herrn.“)

13 Im Mittelalter waren die Konzeptualisierungen von Juden als Teufeln, Teufelsverbündeten, Ritualmördern, Hostienschändern, Ketzern und Hexenmeistern dominant und weit verbreitet (vgl. Trachtenberg 1943: 32 ff.).
} 
und werden daher oft als Teufel(sgenossen) und Satan(sbrut) bezeichnet (s. hierzu Trachtenberg 1943).

Die Spaltung der christlichen Kirche durch Martin Luther bringt keine Kehrtwende. Im Gegenteil: Luther vertieft in seinen Schriften, enttäuscht über das Festhalten der Juden an ihrer Religion, mit wütenden Anklagen die Verteufelung der jüdischen Menschen und trägt durch seine Dämonisierungen ${ }^{14}$ maßgeblich dazu bei, dass auch das Verhältnis der evangelischen Kirche zum Judentum über Jahrhunderte ${ }^{15}$ vergiftet ist:

„Das ists/das ich droben gesagt habe/das ein Christ, nehest dem Teufel / keinen gifftigern / bittern feind habe / denn einen Jüden.“ (Luther [1543] 1577: 378)

(3) „Es stimmet aber alles mit dem vrteil Christi/das sie gifftige/bittere/ rachgierige/ heimische Schlangen/Meuchelmörder vnnd Teuffels Kinder sind / die heimlich stechen vnd schaden thun / weil sie es öffentlich nicht vermügen. Darumb ich gern wollte / sie weren / da keine Christen sind.“ (Luther [1543] 1577: 377)

Auf der Konzeptualisierung, dass die Juden JESUSMÖRDER, MÖRDER DES HEILANDS seien, dass Blut an ihnen klebe und dass sie sich schließlich auch noch dem wahren Glauben widersetzen, entwickelten sich zahlreiche weitere Negativkonzepte, die teils aus (den Juden aufgezwungenen) wirtschaftlich-sozialen Verhältnissen abgeleitet wurden, teils Erfindungen einer auf Feindbild eingestell-

14 Bei der Schrift Von den Jüden und iren Lügen handelt es sich um ein theologisches Traktat, das nicht per se als judenfeindliches Pamphlet zu sehen ist. Dennoch finden sich alle typischen Verbalverteufelungen und die Meinung, man müsse aktiv gegen Juden vorgehen. Als die am häufigsten verwendeten Negativwörter in den Texten Luthers identifiziert Bering (1989b), der sich kritisch und ausführlich mit Luthers Wortschatz beschäftigt hat, vor allem Lüge, lügen, Teufel, schädlich, böse und lästern (Bering 1989b: 148). Bering (1989b: 155) weist auch darauf hin, dass Luther nicht eigens einen judenfeindlichen Wortschatz erzeugte, sondern vielmehr auf bereits existierende pejorative Sprachgebrauchsmuster zurückgriff. Dies schmälert aber natürlich nicht den Einfluss der Schriften auf die kontinuierliche Tradierung der Judenfeindseligkeit mittels der Sprache. Bering (1990) nennt als wichtigen Grund für die erbitterten Verbalattacken Luthers gegen die Juden die Affinität der theologischen Positionen. Dies entspricht der Ressentimentbildung, wie wir sie erläutert haben.

15 Entsprechend wurden Luthers Verbal-Aggressionen oft instrumentalisiert: So von Julius Streicher, der im Nürnberger Prozess 1946 forderte, Luther müsse neben ihm auf der Anklagebank sitzen (s. Bering 1989b: 140). 
ten Betrachtungsweise waren (z. B. RITUALMORDE UND BLUT-VERWENDUNG DER JUDEN; vgl. hierzu Erb 1999 und von Braun 1999). ${ }^{16}$

(4) „Hieraus sihestu nu wol / [...]/ das sie [= die Juden, d. Verf.] dürstige blut Hunde und Mörder sind / der gantzen Christenheit / [...]/Wie sie denn [...] beschüldigt gewest / als hetten sie Wasser und Brün vergiftet / Kinder gestolen / zepfrimet ['mit Pfriemen (Ahlen) durchstochen', d. Verf.] und zu hechelt ['mit Hecheln (Flachskämmen) zerfleischt', d. Verf.] / damit sie an der Christen blut ir mütlin heimlich kületen.“

(Luther [1543] 1577: 345)

(5) „[Die] gottlosen, lästerhaftigen, diebischen, räuberischen und mörderischen [Juden, d. Verf.].“ (Nigrinus 1570: CLXXVII)

(6) „Auf welche unerhoerte Art die Juden Christenkinder gestohlen, demnaechst gemartert, geschunden, gekreuziget, und ihnen das Blut mit Federkielen ausgesogen haben, darueber sind in den glaubwuerdigsten Schriftstellern [...] die zuverlaeßigsten Beispiele vorhanden.“

(Grattenauer ${ }^{3}$ 1803: $12 \mathrm{f}$.)

Die prinzipielle Entwertung der jüdischen Existenz an sich bildete die Grundlage für alle weiteren, über die nachfolgenden Jahrhunderte sich entwickelnden, daraus abgeleiteten und konstruierten Kollektivattribuierungen (JUDEN ALS STARRSINNIG, RACHSÜCHTIG, DIABOLISCH etc.), die weit über die religiösen Unterschiede hinausgingen und das Fundament eines (strikt binären) Weltbildes erschufen (das in den Köpfen vieler Menschen bis heute erhalten ist, wie das aktuelle Beispiel, eine E-Mail an den Zentralrat der Juden aus dem Jahr 2009, zeigt; s. hierzu ausführlich Kap. 5.2).
„ihr seits solz auf gaza???welcher mensch kann stolz auf mord sein?ein antichrist.schon jesus sagte'ihr habt den teufel als vater'.steht in der bibel!mann erkennt arihmans kinder an ihre taten.danke israel ihr habt mir die augen geöffnet.man erntet was man sät! dreimal dürft ihr raten was israel ernten wird in zukunft.ich freue mich schon auf den tag.jener

16 Dieses Konzept wird bis zum heutigen Tag beständig reaktiviert. So lauten Plakattexte auf anti-israelischen Demonstrationen oft folgendermaßen: Israel tötet Kinder/lässt das Blut der Kinder fließen etc. Auch der muslimische Antisemitismus greift viel auf diese Konzeptualisierungen zurück (s. Wistrich 2011: 64 f.). 
tag wird in die kosmische geschichte eingehen, als der tag wo das BÖSE besiegt wurde.“[ZJD_Gaza2009_84/816_Dar_001]

Juden sind diesem Weltbild zufolge nicht in dem einen oder anderen Aspekt anders als Nicht-Juden, sondern sie sind prinzipiell anders und prinzipiell schlecht. Diese mentale Konstruktion führt zu einer kategorialen, kollektiven Feind(bild)erschaffung. Die judeophoben Stereotyp-Projektionen von JUDEN ALS KINDERMÖRDERN, BLUTKULTANHÄNGERN etc. haben nichts mit realen Gegebenheiten zu tun, sondern sind mentale Konstrukte ${ }^{17}$ der sich abgrenzenden NichtJuden. Somit ist alles, was Juden als Juden tun oder nicht tun, per definitionem falsch, und sämtliche Urteile über Juden sind von vornherein Vor-Verurteilungen, die alle auf dem Ressentiment JUDEN SIND SCHLECHT beruhen. In diesem Weltdeutungssystem wurden (und werden) über die Jahrhunderte hinweg alle Übel der Welt nun den verhassten Juden angedichtet: verschwundene und ermordete Kinder, betrügerische Geschäfte, Brunnenvergiftungen, Krankheiten, die Pest, zerstörte Ernten, persönliche Misserfolge, verlorene Kriege, Finanzkrisen. Juden nahmen somit flächendeckend auch die Sündenbock-Funktion in den christlich geprägten Gesellschaftsstrukturen ein.

Bei einigen der tradierten Stereotype wird oft auf historisch reale Begebenheiten verwiesen, z. B. beim Konzept des Juden als HEIMATLOSEM WANDERER. Nach der Zerstörung Jerusalems durch die Römer im Jahre 70 nach Christus kamen viele Juden ins Exil und bildeten in der Diaspora Gemeinschaften. Aus der Ablehnung des Gastvolkes, das keine Integration der Juden wollte, wurde eine negative Eigenschaft auf die Juden projiziert. Seither kursiert das Stereotyp von den Juden als RUHELOSEN WANDERERN, die sich nicht einleben wollen, sondern im „Gastvolk“ Fremde bleiben und entsprechend keine Solidarität entwickeln.

(8) „Zu andern, todten Nationen mag der Jude mitgerechnet werden; aber zu den Deutschen [...] gehört der Jude nicht.“ (Sauerwein 1831: 10)

(9) „Ich will es [= die Vermehrung der Juden, d. Verf.] [...] auch deswegen nicht, weil sie ein durchaus fremdes Volk sind und weil ich den germanischen Stamm so sehr als möglich von fremdartigen Bestandtheilen rein zu erhalten wünsche.“ (Arndt 1814: 188)

17 Diese Dimension der De-Realisierung zeigt sich bis heute als wesentliche Komponente beim Antisemitismus, insbesondere in der Formvariante des Israel dämonisierenden AntiIsraelismus (s. Kap. 7.2.1). 
Aus dem von Nicht-Juden gegen Juden etablierten Verbot, gewöhnlichen gesellschaftlichen Tätigkeiten (wie Handwerksberufen o. Ä.) nachgehen zu dürfen, ergab sich, dass Juden von den Aktivitäten der Gesellschaft bis auf die des Geldhandels ausgeschlossen waren (s. Raphael 1999: 115). Der Vorwurf der NichtJuden gegen Juden als Wucherer und Geldmenschen richtete sich also auf das, was zuvor selbst produziert worden war. ${ }^{18}$ Diese erzeugten, den Juden aufgezwungenen Aktivitäten wiederum wurden im Laufe der Geschichte als typisch jüdische Eigenschaften konzeptualisiert und als Legitimation zur Diffamierung und Diskriminierung benutzt.

\begin{abstract}
„Was seind aber die Jüden? in warheit keine Bekenner / sondern Lästerer vnd schänder Gottes vnd Christi [...] Seind sie auch hochschädliche Leuth / in dem sie müssige Wucherer seind. Sie seind müssige Faullentzer/haben weder Aecker noch Wiesen/können keine Handwercker treiben / auch sonst kein Hand=Arbeit / sondern gehen müssig / lassen vns arbeiten vnd im sauren Schweiß vnsere Nahrung gewinnen/sie vnter dessen nehren sich alle auß der armen Christen Schweiß vnd Blut / vnd leben wohl von dem / so sie durch Wucher vnd Betrug denselben abschinden.“ (Saltzmann 1661, zit. n. Hortzitz 2005: 66 f.)
\end{abstract}

Das Klischee des jüdischen Schacherers und Wucherers wurde zum festen Bestandteil des kollektiven Wissens und verfestigte sich über die Sprache durch entsprechende Floskeln (s. Kap. 5.2). In der Weltliteratur ist das Stereotyp des UNBARMHERZIGEN GELDMENSCHEN prototypisch durch die Figur des Shylock ${ }^{19}$ in Shakespeares Merchant of Venice festgehalten. Die negative Bewertung von Juden

18 Zwischen 325 und 1139 hatte die Kirche auf den verschiedenen Konzilien die Tätigkeit des Zinsverleihs für Christen verboten. Doch die mittelalterliche Wirtschaft war abhängig von Geldgeschäften dieser Art. Selbst Klöster waren zum Teil darauf angewiesen. So kritisierten Geistliche öfters scharf die angebliche Geldsucht der Juden und verurteilten moralisch den Zinsverleih, griffen aber als lebenspraktische Notwendigkeit selbst darauf zurück. Bernhard von Clairvaux (11./12. Jahrhundert) z. B. setzte Juden und Wucher gleich, verurteilte aber zugleich die christlichen Geldverleiher als noch schlimmer als die Juden. Christen, die Wucher betreiben, würden so zu „getauften Juden“. Dies ist die erste bekannte und niedergeschriebene Verwendung des Lexems Jude als Schimpfwort. Wir danken Joseph Shatzmiller für diesen Hinweis.

19 Shatzmiller (2007) konnte allerdings anhand von Zeugenaussagen in einem Gerichtsprozess um einen jüdischen Kaufmann im 14. Jahrhundert zeigen, dass Juden von ihren nicht-jüdischen Zeitgenossen und Handelspartnern als großzügig, hilfsbereit und besonders vertrauenswürdig bewertet wurden. Das allgemein akzeptierte Bild, wonach jüdische Kaufleute und Geldverleiher generell auf Ablehnung und Verachtung stießen, muss also revidiert werden (vgl. hierzu auch Shatzmiller 2007: 9). 
spiegelt sich über die Jahrhunderte hinweg in zahlreichen Schriften wider (und ist in allen Schichten anzutreffen, keineswegs nur beim Straßenmob, den ungebildeten Menschen, sondern bei Dichtern, Denkern, Priestern, Gelehrten, Philosophen). In Goethes Das Jahrmarktsfest zu Plundersweilern werden die Klischees mittels floskelhafter Ausdrücke eher spöttisch (und fiktional aus der Perspektive eines Judenfeindes) aufgezählt; ${ }^{20}$ nichtsdestotrotz spiegeln sie das kulturell verankerte Wissen der Zeit wider, auf das Goethe hier referiert:

\begin{abstract}
„Du kennst das Volk, das man die Juden nennt [...] sie haben einen Glauben / Der sie berechtigt, die Fremden zu berauben [...] Der Jude liebt das Geld und fürchtet die Gefahr. Er weiß mit leichter Müh, und ohne viel zu wagen, / Durch Handel und durch Zins Geld aus dem Land zu tragen [...] Doch finden sie durch Geld den Schlüssel aller Herzen, / Und kein Geheimnis ist vor ihnen wohlverwahrt [...] Sie wissen jedermann durch Borg und Tausch zu fassen; / Der kommt nie los, der sich nur einmal eingelassen.“ (Goethe [1733] 21973: 133 f.)
\end{abstract}

Nicht einmal die Epoche der Aufklärung mit ihrer vernunftorientierten Religionskritik, in der im Namen rationaler Prinzipien gleiche Rechte für alle Menschen und die Aufhebung von Standes- und Klassenschranken gefordert wurden, durchbrach das kulturell gefestigte anti-jüdische Denkmuster: Voltaire betrachtet Juden nicht nur als natürliche Feinde bestimmter Nationen, sondern auch der gesamten Menschheit und bleibt damit exakt der tradierten (religiös fundierten) Konzeptualisierung verhaftet: ${ }^{21}$

„Kraft ihrer eigenen Gesetze, natürliche Feinde dieser Nationen und schließlich der Menschheit.“222 (Voltaire [1761] 1878: 435, zit.n. Hentges 1999: 45)

20 In Goethes Texten finden sich keine Anzeichen für eine judenfeindliche Einstellung (s. Low 1979, Homann 2002). Dennoch wird die oben aufgeführte Stelle vielfach von Rechten und Rechtsextremen zitiert, um die angebliche Skepsis und Antipathie des berühmten Dichters gegenüber Juden zu belegen (s. Schwarz-Friesel 2012a).

21 Vgl. auch Voltaire (1785: 186): „Das jüdische Volk wagt, einen unversöhnlichen Haß gegen alle Völker zur Schau zu tragen. Es empört sich gegen alle seine Meister, immer abergläubisch, immer gierig nach dem Gute anderer, immer barbarisch, kriechend im Unglück und frech im Glück.“ Im Original (Voltaire 1785: 186): „[La nation juive] ose étaler une haine irréconciliable contre toutes les autres nations; elle se révolte contre tous ses maîtres; toujours superstitieuse, toujours avide du bien d'autrui, toujours barbare, rampante dans le malheur, insolente dans la prospérité.“

22 Im Original: „[I]ls se trouvèrent, par leurs lois mêmes, ennemies naturels de ces nations et enfin du genre humain“(Voltaire 1878: 435, zit. n. Hentges 1999: 45). 
Auch in seinem philosophischen Wörterbuch Dictionnaire philosophique werden die Juden in mehreren Artikeln sehr verachtungsvoll erwähnt und unter anderem als „das abscheulichste Volk der Erde“ bezeichnet (s. hierzu Poliakov 1983: 101, vgl. auch Laqueur 2006: 88: „Ich wäre nicht im Geringsten überrascht, wenn dieses Volk eines Tages tödlich für die menschliche Rasse werden würde“).

Die Annahme, dass Feindschaft gegenüber Juden vor allem auf den Mangel an Aufklärung und Bildung zurückzuführen sei, muss daher zurückgewiesen werden: Auch hoch intelligente und sehr gebildete Menschen waren und sind nicht gefeit gegenüber judeophoben Ressentiments (s. hierzu auch Kap. 9). Ein Blick auf die Schriften der großen deutschen Philosophen des Idealismus, die sich der Wahrheitsfindung durch Denkvermögen verpflichteten, macht dies besonders deutlich:

(13) „Die unter uns lebenden Palästiner [= Juden, d. Verf.] sind durch ihren Wuchergeist seit ihrem Exil, auch was die größte Menge betrifft, in den nicht unbegründeten Ruf des Betruges gekommen.“

(Kant [1798] 1839: 218)

(14) „Erinnert ihr euch denn hier nicht des Staates im Staate? Fällt euch denn hier nicht der begreifliche Gedanke ein, dass die Juden, welche ohne euch Bürger eines Staates sind, der fester und gewaltiger ist als die eurigen alle, wenn ihr ihnen auch noch das Bürgerrecht in euren Staaten gebt, eure übrigen Bürger völlig unter die Füsse treten werden? [...] Aber ihnen Bürgerrechte zu geben, dazu sehe ich wenigstens kein Mittel, als das, in einer Nacht ihnen allen die Köpfe abzuschneiden und andere aufzusetzen, in denen auch nicht eine jüdische Idee sey. Um uns vor ihnen zu schützen, dazu sehe ich wieder kein anderes Mittel, als ihnen ihr gelobtes Land zu erobern, und sie alle dahin zu schicken.“

(Fichte [1793] 1845: 150)

Ähnliche Aussagen finden sich bei Herder und Hegel. Hegel, der bedeutendste Philosoph des Idealismus, zeichnete sich in seinen frühen Schriften sogar durch einen besonders intensiven Judenhass aus, der nahezu alle tradierten Stereotype des Anti-Judaismus aufwies, diese jedoch mit seinen philosophischen Reflexionen zum allgemeinen Geist verband (s. hierzu ausführlich Hentges 1999).

$$
\begin{aligned}
& \text { „Nicht zu leugnen sind die verkehrten und unmoralischen Begriffe der } \\
& \text { Juden von dem Zorn, der Parteilichkeit, dem Hasse gegen andere Völker, } \\
& \text { der Intoleranz ihres Jehova, Begriffe, die leider in die Praxis und Theorie } \\
& \text { der christlichen Religion übergegangen sind [...]. - Und wir haben es }
\end{aligned}
$$


nicht ihren Priestern, sondern der Philosophie, von welchen sie deswegen gehaßt wurde, und dem milderen Licht unserer Zeiten zu danken, daß ihre düstere Zanksucht, ihre Intoleranz und ihr Eigendünkel abgenommen hat.“ (Hegel [1793/1794] 1907: 359)

Das jüdische Volk, so Hegel, sei „ohne Seele und eigenes Bedürfnis der Freiheit bei seiner Befreiung gewesen“, isoliere sich gegenüber anderen Menschengruppen, zeichne sich aus durch Menschenverachtung und -hass; es gebe eine jüdische Sucht, sich zu isolieren, Liebe, Geist und Leben seien ihnen fremd geworden und der "Sabbat sei charakteristisch für den sklavischen Geist“. Auch der Vorwurf, Juden seien menschlich niedere, intellektuell minderwertige Wesen und Leugner der wahren Religion, wurde artikuliert:

\begin{abstract}
„Der Geist erkennt nur den Geist; sie sahen in Jesu nur den Menschen, den Nazarener, den Zimmermannssohn, [...] so viel war er, mehr konnte er ja auch nicht sein, er war nur einer, wie sie, und sie selbst fühlten, daß sie Nichts waren. Am Haufen der Juden mußte sein Versuch scheitern, ihnen das Bewußtsein von etwas Göttlichem zu geben, denn der Glaube an etwas Göttliches, an etwas Großes kann nicht im Kote wohnen.“
\end{abstract}

(Hegel [1800] 1907: 312)

Nach über 1.700 Jahren der Diffamierung war die Judenfeindschaft so tief in den abendländischen Denkstrukturen verwurzelt, dass selbst die Dichter und Denker, die sich von der alten Kirchendoktrin lösten und den mentalen Weg für die freie Selbstbestimmung des Menschen ebneten, sich (trotz ihrer Reflexionen über die Anerkennung der Bürgerrechte für alle Menschen) nicht davon lösen konnten. Dies zeigt sehr deutlich, dass Judenfeindschaft nicht nur ideologisch basiert war, sondern im Glaubenssystem der Menschen auf scheinbar unerschütterlichen ethischen Prinzipien bzw. Denkkategorien fußte. Dass diese manichäistischen Denkkategorien erst durch die christliche Kirchendoktrin in die Welt Eingang fanden, wurde nicht reflektiert.

Bis in das späte 18. bzw. frühe 19. Jahrhundert war Judenfeindschaft im Wesentlichen religiös motiviert und ein christlicher Anti-Judaismus (s. u. a. Bauer 1992, Weinzierl 1995, Benz 2004). Konkrete Auswirkungen dieses Anti-Judaismus waren Ausgrenzung, Vorenthaltung von Bürgerrechten und Verfolgung, Zwangstaufen sowie die (in sporadischen Pogromen auftretende) Ermordung von Juden. Die vorherrschenden Stereotype, die sich in der Literatur, in anti-jüdischen Predigten, in Pogromaufrufen und Hetzschriften zeigten, waren die der Juden als JESUSMÖRDER, als HEIMATLOSE WANDERER, als GELDLEUTE, WUCHERER, SCHACHERER und VERSCHWÖRER (vgl. hierzu ausführlich die Einzelartikel in Schoeps/ 
Schlör 1999). Ganz gleich, was Juden über die Jahrhunderte hinweg taten oder nicht taten, ob sie wirtschaftlichen Erfolg und soziales Prestige hatten oder nicht, es wurde aus der ressentimentgeleiteten Perspektive stets nur negativ bewertet. Je nach Perspektive wurden sie daher zeitgleich z. B. als Kapitalisten oder als Sozialisten bzw. Bolschewiken beschimpft (vgl. Barkai 1999 und Niedermüller 1999). In vielen Schriften wurden sie als minderwertige Kreaturen dargestellt, oft mit Tieren verglichen und auf einer niederen Stufe der Existenz angesiedelt:

„Und bei alle diesem Einfluß, Macht, Reichthum und Freyheit waren und sind sie [= die Juden, d. Verf.] die Blutsauger des Volkes [...], bleiben selbst auf der niedrigsten Stuffe der Kultur und verbreiten Schmutz und Rohheit um sich her.“ (Fries 1816: 5)

Hier wird zugleich das Prinzip der Dämonisierung innerhalb der Judeophobie transparent, das über die bloße Sündenbockfunktion hinausgeht: Aus der ursprünglich religiös motivierten Feindseligkeit ist eine absolute Feindschaft geworden, die sich als Ressentiment nicht gegen einzelne Juden, sondern gegen die Existenz der Juden richtet. Im Nationalsozialismus war dieses Ressentiment das Fundament des Erlösungsantisemitismus: ${ }^{23}$ die Ausrottung des Judentums betrieben zum „Guten der Menschheit“, um „Schaden vom deutschen Volke zu bewahren“ (vgl. Katz 1980/1990; s. Kap. 10.3).

\subsection{Erhalt und Resistenz judenfeindlicher Stereotype in der Moderne}

Betrachtet man die Geschichte der Judenfeindschaft, so resultieren die Stereotype über Juden entweder aus dem diskriminierenden Verhalten von Nicht-Juden gegenüber Juden; oder es handelt sich (im weitaus häufigeren Fall) um Konstrukte, die mit der Realität gar nichts zu tun haben, also reine Phantasieprodukte sind (z. B. JUDEN ALS KINDERMÖRDER, ${ }^{24}$ PESTÜBERTRÄGER, MEINUNGSMACHER, WELTVERSCHWÖRER etc.). Stereotype, die über die Manifestationsformen der Sprache teilweise bewusst-intentional, teils unreflektiert seit Jahrhunderten weitergegeben werden, wurden zu einem Kodierungssystem oder, wie Volkov (1990: 29, 2006: 66) es ausgedrückt hat, zu einem „kulturellen und kommunikativen Code“. Aus kognitionslinguistischer Perspektive lässt sich die Jahrhunderte überdauernde Judenfeindschaft als Erhalt eines stabilen mentalen Glaubenssystems

23 Vgl. hierzu auch Bauer (2001) und Friedländer (2006).

24 Vgl. zum Stereotyp RITUALmoRd Erb (1999). 
beschreiben, dessen ideologische Komponenten mit ethisch-moralischen Werten gleichgesetzt und dessen Kenntniseinheiten institutionalisiert kommuniziert werden. Ein konzeptuelles Konstrukt, das maßgeblich auf einem emotionalen Ressentiment basiert, als Glaubenssystem nicht hinterfragt, dem Faktizität unterstellt wird, dessen Gültigkeit als sicher angesehen wird. Ein kognitives Netz von Stereotypkonzepten, die Teil des kollektiven Gedächtnisses, also auf überindividueller Ebene, Bestand des enzyklopädischen Wissens sind.

Diese Stereotypkonstrukte hatten sich bei vielen Menschen zu einem Weltdeutungssystem verdichtet. Aus diesem Weltdeutungssystem heraus entwickelten sich auch radikale Vorschläge, z. B. in Hartwig von Hundt-Radowskys 1819 veröffentlichtem Judenspiegel. Für den hasserfüllten Demagogen waren Juden „Untermenschen“ und „Ungeziefer“, „übelduftende Wiedehopfe“. Er lehnte kategorisch jede Konvertierung oder Assimilation ab: Die ihm zufolge auf immer verderbten Juden müssten ausgemerzt, die Frauen in Bordelle gesperrt werden.

\begin{abstract}
„Am Beßten wäre es jedoch, man reinigte das Land ganz von dem Ungeziefer, und hiezu giebt es gleichfalls zwei Mittel. Entweder, sie durchaus zu vertilgen, oder sie auch, wie Pharao, die Meininger, Würzburger und Frankfurter es gemacht haben, zum Lande hinausjagen [...].“

(Hundt-Radowsky 1819: 144)
\end{abstract}

Natürlich kann man solche Pamphlete als psychopathologische Auswüchse Einzelner sehen, aber die Tatsache, dass der Verfasser nach Erscheinen seiner Schrift nicht in eine städtische Heilanstalt eingeliefert wurde, ${ }^{25}$ belegt die breite Akzeptanz bzw. Gleichgültigkeit gegenüber solchen Gewaltphantasien. ${ }^{26}$

Allgemein etabliert waren komplexe judenfeindliche Deutungsmuster, die alle Wesensmerkmale von Menschen (Aussehen, Charakter, Intelligenz, Sozialverhalten) erfassten. Die physische Erscheinung betreffend wurden Juden als auffällig hässlich mit spezifischen, teuflischen Gesichtszügen, Hakennasen

25 Entsprechend wundert man sich heute auch, dass Hitler mit seinen kruden Verschwörungstheorien und bereits am Anfang seiner politischen Karriere artikulierten Hassphantasien nicht als geistesgestört oder zumindest als mental labil eingestuft, sondern stattdessen zum Reichskanzler bestellt wurde. Eliminierungsforderungen (Juden müssten vertrieben oder umgebracht werden) als „Lösung“ für das ,Judenproblem“ sind bis heute ein zentraler Aspekt judenfeindlicher Argumentation (s. Kap. 10.3).

26 Natürlich wollten keineswegs alle Deutschen Juden tatsächlich vertreiben oder töten, aber wie Low (1979: 7) anmerkt: „the number of Germans who hoped for the disappearance and 'death' of Judaism was quite large: they included adherents of the most diverse political and ideological currents.“ 
und dunklen Haaren sowie Augen charakterisiert. ${ }^{27}$ Der Charakter von Juden wurde mit Attributen wie intellektuelle Minderwertigkeit bzw. Zersetzungskraft, Verschlagenheit, Heuchelei, ränkeschmiedene Falschheit, Listigkeit, Rachsucht beschrieben. Jüdische Frauen zeichneten sich demzufolge durch verderbliche Schönheit im Verbund mit sexueller Attraktivität und Lasterhaftigkeit aus. Hinzu kamen Geiz, Selbstsucht, Unbarmherzigkeit, Gefühlskälte und Feigheit. Juden praktizierten angeblich auch andere Ritualmorde, betrieben Blutkult, waren dem wahren Glauben und den ethischen Werten anständiger Gesellschaften gegenüber halsstarrig sowie blind. Aus der religiösen Glaubensattribuierung, ein auserwähltes Volk zu sein, wurde zudem abgeleitet, Juden seien hochmütig und arrogant.

„Sie [= die Juden, d. Verf.] bilden die arroganteste und exclusivste Aristokratie.“ (Naudh 1861: 7, zit.n. Hortzitz 1988: 161)

Als soziale Wesen schadeten Juden angeblich der Gesellschaft, in der sie als Parasiten, Krankheitserreger, Ausbeuter, Wucherer, Verräter, Zersetzer und einflussreiche Meinungsmacher agierten.

(20) „Judenthum ist mit dem Riesenschmarotzer-Gewaechs [...] zu vergleichen." (Holst 1821: 64)

Ziel der Juden sei es, die Weltherrschaft zu übernehmen und alle Nicht-Juden zu versklaven (s. die Protokolle der Weisen von Zion, vgl. auch das Konzept des WELTJUDENTUMS bei Hitler).

$$
\begin{aligned}
& \text { „Die Juden wollen [...] die Welt regieren.“ } \\
& \text { (Scharff-Scharffenstein 1871: 50) }
\end{aligned}
$$

Alle negativen Eigenschaften gehören der rassistischen Ideologie zufolge zum ganzen Volk, und die Floskel ewiger Jude steht für das Klischee der unveränderbar schlechten Wesensart von Juden mit der Kollektivkonzeptualisierung des gesamten verderbten jüdischen Volkes. ${ }^{28}$

27 Das Spottgedicht Wilhelm Buschs zeugt davon ebenso wie die zahlreichen Postkarten, die Juden entsprechend verzerrt in Karikaturen darstellten (s. hierzu Bajohr 2003): „Kurz die Hose, lang der Rock / Krumm die Nase und der Stock / Augen schwarz und Seele grau, / Hut nach hinten, Miene schlau / So ist Schmulchen Schievelbeiner / (Schöner ist doch unsereiner!)“ (Busch 1882: Kap. 5)

28 Diese Konzeptualisierung hat Bering (2002: 174) wie folgt charakterisiert: „Dem 
„Ich nenne dieses Fremde schon an sich eine Plage und ein Verderben. Es ist noch mehr so zu nennen, weil die Juden ein verdorbenes und entartetes Volk sind.“ (Arndt 1814: 193)

„Eine geschlossene Gesellschaft, welche [...] nur vom Spähen und Lauern lebt, muß geistig verdorben werden.“ (Fries 1816: 16)

Die religiöse Dimension der Judenfeindschaft wurde durch eine säkulare Form verschoben bzw. überlagert: Im 19. Jahrhundert entwickelte sich auf dem religiösen Anti-Judaismus ${ }^{29}$ ein völkisch-rassistischer Antisemitismus, der die prinzipielle Andersartigkeit der Juden als Rasse bzw. als Volk betonte: Der sogenannte Ariergedanke und das Konzept der Ungleichheit von Menschen wurden in der als wissenschaftlich propagierten Rassenlehre in den Vordergrund gerückt und motivierten die Ab- und Ausgrenzung von Juden (vgl. u. a. Gobineau 1853). Juden wurden als fremde Rasse, als Fremdkörper, als Parasiten und als Zersetzer nichtjüdischer Gesellschaften beschrieben. Eugen Dühring (1881) und Houston Stewart Chamberlain ([1899] $\left.{ }^{30} 1944\right)$ waren viel gelesene Autoren von Schriften (die zum Teil in mehreren Auflagen erschienen), welche auf der Basis der angeblichen Wissenschaft von den Rassegesetzen die Menschen bzw. Völker der Welt in höhere und niedere Rassen einteilten, wobei die Juden als minderwertiges und nichtarisches Volk klassifiziert wurden. Dass diese aber aufgrund ihrer unterstellten List und Verschlagenheit in Machtpositionen gelangen konnten, war ebenfalls ein gängiges Klischee. Die Stereotype von Juden als parasitären Ausbeutern und einflussreichen Machtmenschen wurden daher besonders häufig verbalisiert:

„Sie beuten Völker und Regierungen allesamt aus.“

(Dühring 1881: 121)

\footnotetext{
Antisemiten gelten Juden ihrer gesamten Natur nach als schlecht und in ihren negativen Eigenschaften als unverbesserlich. Wegen dieser notwendig anwesenden Charaktermerkmale sind Juden immer als Kollektiv zu betrachten, das den Gesellschaften, in denen es lebt, wesensfremd bleibt und einen verdeckten destruktiven Einfluss auf das 'Gastvolk' ausübt. Dieser negative Einfluss und die faktische Fremdheit müssen entlarvt werden, um das wahre, unveränderliche Wesen der Juden hervortreten zu lassen.“

29 Die säkulare und rassistische Judenfeindschaft ist keineswegs radikal anders als der religiöse Anti-Judaismus. Die Feindseligkeit verschärft sich nur dadurch, dass zu den alttradierten Stereotypen und Ressentiments neue Dimensionen der Entwertung von Juden kommen, die pseudo-rational durch die Rassenlehre als wissenschaftlich verbrämt werden. Die Judenfeindschaft hat „mehrere historische Schichten, wobei die älteren Vorurteilsschichten in der nächsten Phase nicht 'vergessen', sondern nur von neuen überlagert wurden“ (Bergmann 2001: 38).
} 
„In der Reichshauptstadt Berlin hat in der Stadtvertretung die Judenrace die Herrschaft [...] von anderen verjudeten Städten [...] will ich garnicht reden.“ (Dühring 1881: 123)

Wörter wie Entjudung und Mischlinge, Charakter der Judenrace, die allesamt dem semantischen Netz der rassistischen Ideologie zuzuordnen sind, wurden benutzt, um auf die Gefahren, die von der „zerfahrenen Race“ (Dühring 1881: 158) ausgehen, hinzuweisen. Dühring (1881: 119f.) griff auch „die Judenfrage“ als Problem auf und diskutierte ernsthaft „Lösungen“ wie „Reductionsmittel“, „Agitation“ und „Gesetzgebung“ gegen die „Judenherrschaft“ und die „überwuchernde Judenmacht“ als vorläufiges „Hilfsmittel“ und „Unschädlichkeitmachung“ und kam zu dem Schluss: „Die Abschüttelung des Judenalps ist eine Angelegenheit der Nationen" (Dühring 1881: 154).

Ähnliche Passagen finden sich bei Adolf Stoecker, ${ }^{30}$ dem Berliner Theologen und Hofprediger, aber auch in den politischen Parteiprogrammen der Jahre 1884 bis 1906 (s. de Lagarde 1884 und Friesel 2006). So betonte Paul de Lagarde (1884: 88 ff.) im Programm für die konservative Partei Preußens 1884, „daß die Juden nicht eine Religionsgenossenschaft, sondern eine Nation ausmachen“, wobei „keine Nation [...] so in jeder Hinsicht wertlos gewesen [sei] wie die jüdische“ (de Lagarde 1884: 89) und „die Juden als Juden in jedem europäischen Volke ein schweres Unglück sind“ (de Lagarde 1884: 91). Die Ausführungen basieren auf einer strikten kategorialen Abgrenzung von Deutschen und Juden, die sich im 19. Jahrhundert auf allen institutionellen Ebenen fand. In den meisten Schriften, die sich mit der „Judenfrage“ oder dem „Judenproblem“ in Deutschland beschäftigten, wurden wiederholt stets die gleichen Lösungen als Forderungen an die angeblich nicht-deutschen Juden gestellt derart, dass „die Juden aufhören, Juden zu sein" (de Lagarde 1884: 95). In seiner Schrift Juden und Indogermanen aus dem Jahr 1887 hielt de Lagarde zudem fest:

$$
\begin{aligned}
& \text { „Es gehört ein Herz von der Härte der Krokodilshaut dazu, um mit den } \\
& \text { armen ausgesogenen Deutschen nicht Mitleid zu empfinden und - was } \\
& \text { dasselbe ist - um die Juden nicht zu hassen, um diejenigen nicht zu } \\
& \text { hassen und zu verachten, die - aus Humanität! - diesen Juden das Wort } \\
& \text { reden oder die zu feige sind, dies Ungeziefer zu zertreten. Mit Trichinen } \\
& \text { und Bazillen wird nicht verhandelt. Trichinen und Bazillen werden auch }
\end{aligned}
$$

30 Stoecker war Mitbegründer der „Berliner Bewegung“, die 1880/1881 die sogenannte „Antisemitenpetition“ mit dem Ziel initiierte, die rechtliche Gleichstellung der Juden in Deutschland einzuschränken. Die Petition wurde von einer Viertelmillion Menschen unterzeichnet. 
nicht erzogen, sie werden so rasch und so gründlich wie möglich vernichtet.“ (de Lagarde 1887: 339)

Juden mittels Tiermetaphorik als lebensunwerte Schädlinge zu klassifizieren, ist also keineswegs eine Besonderheit der Nationalsozialisten gewesen.

Entsprechend lautete eine Passage auch im Programm der deutsch-sozialen Partei (Leipzig 1905) folgendermaßen:

\begin{abstract}
„Als eine zersetzende Kraft [...] unseres Volkslebens hat sich das stammfremde jüdische Volk erwiesen. Und so erscheint uns der Kampf gegen die Macht des Judentums als eine sittliche, politische und wirtschaftliche Notwendigkeit.“ (Salomon ${ }^{31924: ~ 155) ~}$
\end{abstract}

Und im Tivoli-Programm der großen und einflussreichen Partei der Deutsch-Konservativen war 1892 festgehalten:
„Wir bekämpfen den vielfach sich vordrängenden und zersetzenden jüdi- schen Einfluss auf unser Volksleben. Wir fordern für das christliche Volk eine christliche Obrigkeit und christliche Lehrer für christliche Schüler.“ (Salomon ${ }^{3}$ 1924: 65)

Nach modernen Bewertungsmaßstäben lesen wir diese Texte, deren Semantik für uns nur Rassismus, Extremismus und Psychopathologie transparent machen, heute mit Verwunderung und Abscheu, doch die diese Texte lesenden Zeitgenossen der Verfasser nahmen das darin zum Ausdruck kommende Gedankengut als selbstverständlich und diskussionswürdig auf. Spuren der tief und breit verwurzelten Judenfeindschaft waren sprachlich ${ }^{31}$ und bildhaft auf Postkarten mit gehässigen Karikaturen, ${ }^{32}$ in Briefen, Romanen, Pamphleten, auf Schildern, in Prospekten, philosophischen, theologischen, historischen, ökonomischen und

31 Im 19. Jahrhundert war somit ein „sprachlich fixiertes Vorurteilssystem eingeübt und festgeschrieben“ (Bering 1991: 342), dessen Fundament allerdings fast 2000 Jahre zuvor bereits gelegt wurde.

32 Fuchs (1921: 104) beschreibt das anti-jüdische Ressentiment 1921 bereits sehr treffend: „Die Karikatur tritt gegenüber den Juden fast immer in der Rolle des Anklägers auf. Darum offenbaren die meisten antijüdischen Karikaturen je nach den Umständen einen mehr oder minder großen Haß und zugleich eine Verachtung, die alle Grade in sich birgt, und nicht selten bis zur letzten Grenze geht. [...] Aus manchen Judenkarikaturen spricht sogar in nicht mißzuverkennender Weise eine sich ohnmächtig fühlende Wut gegen den angeblichen Todfeind der christlichen Gesellschaft, den man haßt, verachtet, fürchtet, und dem man dabei doch nicht so an den Kragen gehen kann, wie man in seinen heimlichen Wünschen gerne möchte.“ 
politischen Abhandlungen zu sehen; die judeophobe Kommunikation war also ein integraler Bestandteil auf allen Ebenen des öffentlichen, gesellschaftlichen Lebens.

$$
\begin{aligned}
& \text { „Der Jude arbeitet nicht, sondern läßt die anderen arbeiten; er spekuliert } \\
& \text { und macht Geschäfte mit den Produkten der Handarbeit und der geisti- } \\
& \text { gen Arbeit von anderen. Das Zentrum seiner Aktivitäten ist die Börse [...]. } \\
& \text { Dieser fremde Stamm hat sich im deutschen Volk eingenistet, um es bis } \\
& \text { aufs Mark auszusaugen.“ (Glagau 1878: } 16 \text { f.) }
\end{aligned}
$$

Auch die Sphären von Kunst, Musik und Literatur ${ }^{33}$ waren nicht ausgeschlossen: Als symptomatisch für das antisemitische Gedankengut des „ästhetischen Rassismus“ mit seinen generischen Kollektivattribuierungen im 19. Jahrhundert ist die Schrift Richard Wagners Das Judenthum in der Musik zu betrachten (vgl. u. a. Katz 1986), in der sich rassistische Abwertung und Neid auf den Erfolg jüdischer Künstler verbanden:

(30) „Der Jude, der an sich unfähig ist, weder durch seine äußere Erscheinung, noch durch seine Sprache, am allerwenigsten aber durch seinen Gesang, sich uns künstlerisch kundzugeben, hat nichtsdestoweniger es vermocht, in der verbreitetsten der modernen Kunstarten, der Musik, zur Beherrschung des öffentlichen Geschmacks zu gelangen.“ (Wagner 1850: 73)

Das Judentum war Wagner zufolge inhuman und müsse aufgegeben werden, eine für das 19. Jahrhundert typische Forderung an die in Deutschland lebenden Juden:

„Gemeinschaftlich mit uns Mensch werden, heißt für den Juden [...]: aufhören, Jude zu sein.“ (Wagner 1850: 85)

Bilder von Juden als Spekulanten und Wucherer, als böse und hässliche Ganoven, als herzlose, kalte Geschäftsleute oder zersetzende, unmoralische Intellektuelle finden sich auch in zwei im 19. Jahrhundert viel gelesenen Romanen der an sich liberal gesinnten Autoren ${ }^{34}$ Gustav Freytag (Soll und Haben, 1855) und Wilhelm

33 In Grimms Märchen findet sich bis 1945 der Text Der Jude im Dorn, in dem eine grausame, judenfeindliche Szene enthalten ist, die körperliche Gewalt gegen Juden rechtfertigt und das Klischee des Geldjuden bedient. Der als Betrüger entlarvte Jude wird am Ende hingerichtet.

34 Vgl. auch Äußerungen von Theodor Fontane wie (s. Benz 2001: 9, 58 f.): „Hier war es, mit 
Raabe (Der Hungerpastor, 1864). Diese artikulierten in ihren Schriften, Briefen und Romanen tradierte judenfeindliche Stereotype und Gefühle der Abneigung, ohne dass man diese Verfasser immer als glühende Judenhasser hätte charakterisieren können. Es gehörte aber zum kulturell-kommunikativen Erbe, judenfeindliche Animositäten zu verbalisieren; als Teil des kollektiven Bewusstseins war es keine Besonderheit, sondern gehörte vielmehr habitualisiert dazu, war eine Selbstverständlichkeit, die oft nicht reflektiert wurde. Dehumanisierende Beschreibungen und Metaphern traten in Verbindung mit tradierten Stereotypen auf:

„[...] und in dem Viereck [...] windet sich aalglatt der jüdische Faktor hindurch [...].“ (Freytag 1855: 490)

Der Jude Veitel Itzig wird klischeebelastet mittels judeophober Floskellexik beschrieben:

(33) „Es war das Gesicht eines Teufels, [...] rotes Haar stand borstig in die Höhe, Höllenangst und Bosheit saß in den hässlichen Zügen.“

(Freytag 1855: 386)

Die Wohnung des Juden Ehrenthal wird mittels Personifikation als charakterlos gekennzeichnet, und der Vergleich mit der Zigeunerin knüpft an das Stereotyp des Fremden, des Heimatlosen an. Zudem wird die Geschmacklosigkeit seiner Familie betont (Freytag 1855: $175 \mathrm{f}$.):

(34) „Es war kein guter Charakter in dem Hause, wie eine alte Zigeunerin sah es aus.“

$$
\text { „[...] und die zahlreichen schlechten Ölbilder an den Wänden [...]“ }
$$

Auch in Raabes Hungerpastor werden der Protagonist Hans Unwirsch und der Antagonist Moses Freudenstein kontinuierlich mittels kontrastierender, polarisierender Darstellungen beschrieben. (36) und (37) sind hierfür typische Beispiele:

(36) „Rührend war die ehrfurchtsvolle Scheu, welche Hans [...] wahrhaft diabolisch aber war die Art und Weise, in welcher Mose [...] diesem Glauben an die Autorität ein Bein zu stellen suchte.“ (Raabe 1864: 137)

Ausnahme der Juden, sehr schön.“ 

„Hans Unwirsch fühlte zum ersten Mal in seinem Leben, was der Haß sei; er haßte die schlüpfrige, ewig wechselnde Kreatur, die sich einst Moses Freudenstein nannte, von diesem Augenblick an mit ganzer Seele.“ (Raabe 1864: 295)

In beiden Romanen finden sich ähnliche Beschreibungen, die lexikalisch auf dieselben semantischen Felder zurückgreifen: Fokussiert ist das Dämonische (vgl. „Gesicht eines Teufels“ und „diabolisch“), das Unberechenbare und Dehumanisierte (vgl. „aalglatt“ und „schlüpfrig“), das Undeutsche (so wird in beiden Romanen das Jiddische der jüdischen Personen nachgeahmt und deren fremdländisches Aussehen betont) und Anti-Christliche (die Konvertierung Freudensteins wird als opportunistische Fehlhandlung entwertet).

Auch Theodor Fontane ließ wiederholt erkennen, dass ihm eine judenfeindliche Einstellung zu eigen war. So stellte er in einem Brief aus Norderney 1882 fest:
„Fatal waren die Juden; ihre frechen, unschönen Gaunergesichter (denn in Gaunerei liegt ihre ganze Größe) drängen sich einem überall auf. Wer in Rawicz oder Meseritz ein Jahr lang Menschen betrogen oder wenn nicht betrogen, eklige Geschäfte besorgt hat, hat keinen Anspruch darauf, sich in Norderney unter Prinzessinnen und Comtessen mit herumzuzieren.“ (zit. n. Fleischer 1995: 84)

Fontane äußerte sich in seiner privaten Briefkorrespondenz mehrfach negativ mit generischen Aussagen wie „Borkum ist judenfrei“ bezüglich der Juden (s. auch Fußnote 34; vgl. Fleischer 1995: 84; s. auch Benz 2001: 9, 58 f.). 1898 finden sich bei ihm eindeutig rassistische Formulierungen:

(39) „Überall stören sie (viel mehr als früher), alles vermanschen sie, hindern die Betrachtung jeder Frage als solcher. Es ist, trotz all seiner Begabungen, ein schreckliches Volk, nicht ein Kraft und Frische gebender 'Sauerteig', sondern ein Ferment, in dem die häßlicheren Formen der Gärung lebendig sind - ein Volk, dem von Uranfang an etwas dünkelhaft Niedriges anhaftet, mit dem sich die arische Welt nun mal nicht vertragen kann. Welch Unterschied zwischen der christlichen und jüdischen Verbrecherwelt. Und das alles unausrottbar.“

(zit. n. Paulsen 1981: 310, s. auch Goldammer 1993: 54 f.) 
Der Ausdruck Antisemitismus wurde erst 1879 von dem Journalisten Wilhelm Marr ${ }^{35}$ geprägt, um über eine Bezeichnung für die sich als wissenschaftlich motiviert verstandene, säkulare Richtung der Judenablehnung in Abgrenzung zur religiösen Judenfeindschaft zu verfügen (s. auch Berger Waldenegg 2000, Bergmann 32006: 6 ff. und Rensmann 2004: 71 f.). In Marrs Schrift Der Sieg des Judenthums über das Germanenthum finden sich zahlreiche Konzeptualisierungen, die dominant im 19. Jahrhundert waren (JUDEN ALS INTELLEKTUELLE MEINUNGSBILDNER IN PRESSE UND FINANZPOLITIK, JUDEN ALS FREMDE UND ANDERSARTIGE, JUDEN ALS ZERSETZER CHRISTLICHER GESELLSCHAFTEN), versprachlicht (s. hierzu auch Zimmermann 1986 und 2005: 112 ff.). Die nachfolgenden Beispiele sind alle dieser Schrift entnommen.

Juden zeichnen sich Marr zufolge dadurch aus, dass sie „zum Schaden des Germanenthums agieren, das Germanische zu zersetzen und zerstören. "Er bezeichnet sie als „die Fremdlinge“, „die semitischen Fremdlinge“, „dieses fremde Volk“, „fremder Volkstamm“ (Marr ${ }^{3} 1879:$ 14). Es finden sich zudem auch die tradierten, anti-judaistischen Stereotype DES WUCHERERS, DES DEMAGOGEN, DES RACHSÜCHTIGEN und die These von der Weltverschwörung:

„Geldmenschen, [...] vaterlandslos“ (14), „[...] wuchern, [...] haben Schacher- und Wuchergeist, [...] scheuen sich vor wirklicher Arbeit, [...] hochbegabt, hochtalentiert“ (13), „[...] feindselig gegenüber anderen, [...] glatt, [...] listig, [...] elastisch“ (14), „dominant, einflussreich“ (23), „,...] verjudete Tagespresse, [...] rachsüchtig“ (50)

Hier manifestiert sich eine Judeophobie, die sich zwar vom religiös begründeten Anti-Judaismus distanziert und bei der vordergründig keine theologischen Überlegungen oder religiösen Motive maßgeblich sind, die jedoch weiterhin die uralten Ressentiments pflegt und auf der tradierten Dichotomisierung basiert. Marr erweist sich mit dieser Schrift auch dadurch rhetorisch und argumentativ

35 Laut Nipperdey und Rürup (1994: 138) findet sich „der erste bisher bekannte Beleg [...] in der 'Allgemeinen Zeitung des Judentums' vom 02.09.1879.“ Unter dem Absatz „Streitschriften für die Juden“ heißt es: „Wir erhalten von Hamburg eine anonyme Correspondenz, deren Inhalt wir daher in keiner Weise verbürgen. Danach soll Marr's Pamphlet die zehnte Auflage erreicht haben - darauf käme es nun wenig an, vielmehr auf die Höhe der Auflagen - er will es als Tractätchen in 150.000 Exemplaren verbreiten - wir wollen abwarten, ob er dies ausführen könne - er habe Freunde gefunden und durch diese werde das 'antisemitische Wochenblatt' zu Stande kommen [...]“ (AZdJ 1879: 564). Etymologisch und semantisch betrachtet macht dieser Begriff keinen Sinn, da es kein Anti gegen Semiten gibt. Es geht ausschließlich um Juden und nicht etwa um semitische Völker (s. hierzu auch Berger Waldenegg 2000 und Bauer 2011). 
als ein Vorläufer der aktuellen Judenfeindschaft, ${ }^{36}$ indem er auf die Faktizität seiner judendiffamierenden Aussagen pocht und sie als unzweifelhafte Wahrheiten ausgibt. Er, so Marr (31879: 33, 55), habe „keine üble Absicht“, sondern beziehe sich vielmehr „auf Thatsachen“, „unumstössliche und historische Thatsachen“.

Durch einen Artikel des Historikers Heinrich von Treitschke wurde 1879 der sogenannte Berliner Antisemitismusstreit in Akademikerkreisen ausgelöst ${ }^{37}$ (s. Boehlich 1965 und Volkov 2006: 22 f.). Der angesehene Historiker hatte sich gegen die von ihm befürchtete Masseneinwanderung osteuropäischer Juden ausgesprochen, und den deutschen Juden warf er mangelnden Assimilationswillen vor.

\begin{abstract}
„Was wir von unseren israelitischen Mitbürgern $\mathrm{zu}$ fordern haben, ist einfach: sie sollen Deutsche werden, sich schlicht und recht als Deutsche fühlen - unbeschadet ihres Glaubens und ihrer alten heiligen Erinnerungen, die uns Allen ehrwürdig sind; denn wir wollen nicht, daß auf die Jahrtausende germanischer Gesittung ein Zeitalter deutsch-jüdischer Mischcultur folge [...]. Es bleibt aber ebenso unleugbar, daß zahlreiche und mächtige Kreise unseres Judenthums den guten Willen schlechtweg Deutsche zu werden durchaus nicht hegen.“
\end{abstract}

(Treitschke 1879: 573, zit.n. Boehlich 1965: 10)

Rassistische Vorstellungen verbanden sich mit christlichem Überlegenheitsgefühl und Intoleranz auch im Bildungsbürgertum:

\begin{abstract}
„[...] so erscheint die laue Agitation des Augenblicks doch nur als eine brutale und gehässige, aber natürliche Reaction des germanischen Volksgefühls gegen ein fremdes Element, das in unserem Leben einen allzu breiten Raum eingenommen hat [...]. Aber der Gegensatz läßt sich mildern, wenn die Juden, die so viel von Toleranz reden, wirklich tolerant werden und einige Pietät zeigen gegen den Glauben, die Sitten und
\end{abstract}

36 Der Glauben, hinsichtlich der Ablehnung von Juden und Judentum im Recht zu sein und nur auf Fakten hinzuweisen, ist auch heute ein typisches Kennzeichen antisemitischen Denkens und Sprechens: Moderne Antisemiten sind blind und taub für alles, was ihrem konzeptuell geschlossenen Welt- und Feindbild nicht entspricht, und deklarieren ihre gegen Juden gerichteten Forderungen z. B. als humanistisch motiviert (vgl. Kap. 9 und 11.2).

37 Die öffentliche Debatte ließ in den Kommentaren der Leser tiefe Emotionen zum Vorschein kommen: So schrieb z. B. ein junger Mann aus Greifswald, Student bei Treitschke (Boksch 1880, zit. n. Benz 2001: 64 f.): „Ich hasse die Juden nicht, aber ich hasse das Judenthum. Das Wesen der Juden widersteht mir, und in diesem Gefühl fühle ich wie ein Germane. Niemals wird der Deutsche das französische Wesen so widerwärtig finden, so hassen können, als das jüdische. Deshalb ist auch 'Antisemit' viel richtiger gesagt als ‘Antijud'.“ 
Gefühle des deutschen Volks, das alte Unbill längst gesühnt und ihnen die Rechte des Menschen und des Bürgers geschenkt hat.“

(Treitschke 1879: 575 f., zit. n. Boehlich 1965: 11 f.)

Treitschke produzierte in seiner Schrift den Satz, der in der NS-Zeit als permanente Stürmer-Schlagzeile instrumentalisiert wurde: „die Juden sind unser Unglück!“38 In diesem Satz, mit dem Treitschke seine Auffassung ausdrückte, die Juden hätten einen destruktiven Einfluss auf das kulturelle und wirtschaftliche Leben des deutschen Staates, spiegelt sich erneut die wesentliche Konstante der Judenfeindschaft wider: die irreale, hyperbolische und dämonisierende Weltphantasie von der negativen Rolle der Juden. Die Juden stellten kaum ein Prozent der deutschen Bevölkerung ${ }^{39}$ und waren schwerlich in der Lage, das Unglück Deutschlands zu sein. Kein Historiker zweifelt heute mehr daran, dass sie überhaupt keinen Einfluss hatten auf das, was sich im Kaiserreich entwickelte. Die Geschichte der Judenfeindschaft zeigt jedoch eines besonders deutlich: Nicht die realen Gegebenheiten spielten bei der Diffamierung und Diskriminierung von Juden je eine Rolle, sondern ausschließlich die mentalen Bilder, die geistigen Vorstellungen, die in der jeweiligen Gesellschaft kollektiv in den Köpfen der Menschen verankert waren. Diese Konzeptualisierungen wiederum fußten auf einem dichotomen Bewertungssystem, welches das Judentum per se als nicht-legitime bzw. im Vergleich zum Christentum minderwertige Religion einstufte. Und so kam selbst der liberale Theodor Mommsen, der sich vehement gegen Treitschke wandte und engagiert für die vollen Bürgerechte sowie die Integration der jüdischen Mitbürger einsetzte, daher nicht umhin, diesen ihr Judentum als Hindernis für eine volle Eingliederung in die christlich geprägte Gesellschaft vorzuwerfen:

\begin{abstract}
„Die Schuld davon liegt allerdings zum Theil bei den Juden. Was das Wort 'Christenheit' einstmals bedeutete, bedeutet es heute nicht mehr voll; aber es ist immer noch das einzige Wort, welches den Charakter der heutigen internationalen Civilisation zusammenfasst und in dem Millionen und Millionen sich empfinden als zusammenstehende auf dem völkerreichen Erdball.“ (Mommsen 1880: 114)
\end{abstract}

38 Der volle Satz lautet (Treitschke 1879: 575): „Bis in die Kreise der höchsten Bildung hinauf, unter Männern, die jeden Gedanken kirchlicher Unduldsamkeit oder nationalen Hochmuths mit Abscheu von sich weisen würden, ertönt es heute wie aus einem Munde: die Juden sind unser Unglück!“ Treitschkes Äußerungen verursachten eine politische Polemik, die sich über zwei Jahre hinstreckte (s. Boehlich 1965, Meyer 1966, Krieger 2002).

39 Vgl. Friesel (1990: 104). 
Dieser (aus heutiger Sicht) nicht-intentional artikulierte Antisemitismus zeigt, wie tief eingegraben in den Denk- und Gefühlsstrukturen der abendländischen Welt die Konzeptualisierung des christlichen Leitbildes und das Gefühl von dessen Überlegenheit war. Auch Rudolph Steiner, Begründer der Anthroposophie, war kein (aktiver) Antisemit. Den Antisemitismus lehnte er als „Gefahr sowohl für Juden als für Nichtjuden“ und als „Kulturkrankheit" ab und kritisierte die Protokolle der Weisen von Zion als Fälschung (vgl. Steiner 1919). Doch in seinen Texten finden sich Passagen, die belegen, wie normal es im 19. und frühen 20. Jahrhundert war, pejorative Attribuierungen und Einschätzungen gegenüber Juden zu verbalisieren.

„Es ist gewiss nicht zu leugnen, dass heute das Judentum noch immer als geschlossenes Ganzes auftritt und als solches in die Entwicklung unserer gegenwärtigen Zustände vielfach eingegriffen hat, und das in einer Weise, die den abendländischen Kulturideen nichts weniger als günstig war.

Das Judentum als solches hat sich aber längst ausgelebt, hat keine Berechtigung innerhalb des modernen Völkerlebens, und dass es sich dennoch erhalten hat, ist ein Fehler der Weltgeschichte, dessen Folgen nicht ausbleiben konnten. Juden, die sich in den abendländischen Kulturprozess eingelebt haben, sollten doch am besten die Fehler einsehen, die ein aus dem grauen Altertum in die Neuzeit herein verpflanztes und hier ganz unbrauchbares sittliches Ideal hat. Den Juden selbst muss ja zuallererst die Erkenntnis aufleuchten, dass alle ihre Sonderbestrebungen aufgesogen werden müssen durch den Geist der modernen Zeit.“ (Steiner 1888: 152)

Der Blick auf das 19. Jahrhundert zeigt, dass weder die zunehmende Säkularisierung in Europa noch der technologische Fortschritt, nicht die tiefgreifenden politischen Veränderungen noch die Bildungs- und Sozialreformen oder die frühen Formen demokratischer Strukturen wie Pressewesen und sozialkritische Literatur die Vorbehalte gegenüber Juden und Judentum zerstörten (s. Reinharz 1975). Judenfeindschaft war längst zum Kulturgut ${ }^{40}$ geworden, gehörte als kom-

40 Daher ist jeder Vergleich zu anderen Formen von Vorurteilen (z. B. gegenüber Muslimen) abwegig und verschleiert den Blick für die unikale Komponente der Judenfeindschaft. Judenfeindschaft ist kein Vorurteilssystem unter vielen, sondern eine seit zweitausend Jahren tradierte Welterklärungsideologie. Demgemäß eignet sich die Antisemitismusforschung auch nicht als Paradigma für allgemeine Vorurteilserklärungen. S. hierzu Schwarz-Friesel/Friesel (2012). 
munikatives System habitualisiert zum Zeitgeist, wurde entsprechend als normal empfunden und tradierte sich sprachlich über Floskeln und Redewendungen sowie verzerrende Bilder und Karikaturen, gehörte so selbstverständlich zum Alltag, dass auch im Bildungsbürgertum keine kritische Auseinandersetzung und Distanzierung stattfand. Judenfeindliche Einstellungen waren auf allen gesellschaftlichen Ebenen und in fast allen institutionellen Einrichtungen und Eliten des Kaiserreichs anzutreffen und sie hatten weitreichende Konsequenzen. Jüdische Deutsche hatten zum Teil gravierende Probleme, in Ämter zu kommen oder Mitgliedschaften bzw. Positionen zu erlangen. In vielen Kreisen und Lebensbereichen war eine offen artikulierte antisemitische Abwehrhaltung geradezu als normal zu verzeichnen (vgl. u. a. Leschnitzer 1956: 170 ff., Volkov 2006: 256 f.).

\title{
4.3 Antisemitismus als Staatsdoktrin: Die Endlösung als letzte Konsequenz des Judenhasses
}

\begin{abstract}
„Ideologisches Denken ist, hat es einmal seine Prämisse, seinen Ausgangspunkt, statuiert, prinzipiell von Erfahrungen unbeeinflussbar und von der Wirklichkeit unbelehrbar.“ (Arendt 1955: 742)
\end{abstract}

In der NS-Zeit erreichte der rassistische Antisemitismus ${ }^{41}$ seinen Höhepunkt und mündete schließlich in der Realisierung des eliminatorischen Antisemitismus, der auf die im 19. Jahrhundert bereits gestellte „Judenfrage“ (s. Dühring 1881: $119 \mathrm{f}$.) als Antwort die Auslöschung dieses als minderwertig und schädlich erachteten Volkes gab (vgl. u. a. Bauer 1982, Longerich 1998, Friedländer 2006). Der eliminatorische Antisemitismus unter den Nationalsozialisten ist nur vor dem Hintergrund der jahrhundertealten Judenfeindschaft zu erklären. Jeder Versuch, die deutsche Judenpolitik im Dritten Reich aus dem historischen Zusammenhang, in den diese untrennbar eingebettet ist, $\mathrm{zu}$ reißen und diese als isoliertes Phänomen zu betrachten, ist daher zum Scheitern verurteilt. Die extreme Juden-

41 Vgl. die „wissenschaftliche“ Definition des sogenannten Rasse-Günther, in der NS-Zeit Professor an der Universität Jena. Rasse ist ihm zufolge „eine Menschengruppe, die sich durch die ihr eignende Vereinigung körperlicher Merkmale und seelischer Eigenschaften von jeder anderen [...] Menschengruppe unterscheidet und immer wieder nur ihresgleichen zeugt.“ Geistige Wesensart, Geisteshaltung, Charakter oder schöpferisches Wesen sind an bestimmte körperliche Merkmale gebunden (Günther 1936: 65, in Stuckart/Globke 1936, zit. n. Priester 2003: 239). Globke war später unter Adenauer Staatssekretär. Zu Kontinuität und Diskontinuität des rassistischen Antisemitismus s. Volkov (1990). Vgl. auch von Braun/Gerlach (2000). 
feindschaft der Nazis war nicht eine temporäre Verwirrung in den Jahren 1933 bis 1945, ausgeführt von einigen wenigen verblendeten Verbrechern, sondern sie hatte eine zweitausendjährige Geschichte der wechselnden Transformationen hinter sich, auf der Hitler und seine Anhänger aufbauten.

Schon zu Beginn seiner politischen Aktivitäten propagierte Hitler (zusammen mit den anderen Gründungsmitgliedern der NSDAP, s. Adam 2003) einen extremen Antisemitismus. Seine 1920 in München gehaltene Rede Warum wir Antisemiten sind offenbarte bereits seinen durch Vorurteile und spezifisch antisemitische Konzeptualisierungen genährten Hass. Er griff die für den Rasseantisemitismus typischen Stereotype des 19. Jahrhunderts auf (vgl. (45) und (46)) und kombinierte sie argumentativ für seine spezifische Feindbildkonstruktion:

„Und bei dem allen müssen wir sehen, dass es hier keine guten und keine bösen Juden gibt, es arbeitet hier jeder ganz genau der Bestimmung seiner Rasse entsprechend, denn die Rasse oder wollen wir lieber sagen Nation und was damit zusammenhängt Charakter, usw. liegt, wie der Jude selbst erklärt, im Blut, und dieses Blut zwingt jeden Einzelnen, entsprechend diesen Grundsätzen zu handeln [...].“

(Hitler 1920, zit. n. Phelps 1968: 415)

(46) „Für ihn gibt es kein seelisches Empfinden, und wie sein Erzvater Abraham schon sein Weib verkuppelt, so findet er nicht besonderes daran, wenn er auch heute Mädchen verkuppelt, [...] daß alle diese Mädchenhändler nur Hebräer sind. Man kann hier mit Material aufwarten, das grauenhaft ist. Dem germanischen Empfinden gäbe es hier nur eine einzige Strafe: die Strafe wäre Tod.“

(Hitler 1920, zit. n. Phelps 1968: 414)

Es zeigt sich eine geschlossene Konzeptualisierung, in welcher der (von Natur aus) verbrecherische Jude die Welt beherrschen und das durch Räubereien angeeignete Kapital unter seinesgleichen aufteilen und benutzen will, um dem deutschen Volk Schaden zuzufügen. Hier kommt der dem Antisemitismus eigene extreme Dualismus ${ }^{42}$ zum Ausdruck, der in Mein Kampf wiederholt fokussiert

42 Die rassistisch-antisemitische Konzeptualisierung basiert auf einer strikt binären Kodierung: Auf der einen Seite die homogene, generell positiv bewertete Wir-Gruppe, die das positive Prinzip verkörpert und dieses existenziell verteidigen muss gegen die allgemein negativ evaluierte Ihr-(Die-Anderen-)Gruppe der Juden, die das böse Prinzip verkörpern (vgl. Wistrich 1999, Rensmann 2004). Diese Konzeptualisierung geht meist mit einer ausgesprochenen Dämonisierung einher (vgl. Befu 1999). 
wird: Menschliche Existenz wurde als ein Daseinskampf zwischen Ariern und Juden, die für das Gute und Böse in der Welt stehen, gesehen (Hitler 1934: 317). Feindbildkonstrukte, die rassistische und politische Elemente kombinieren, führten zu Weltverschwörungsfiktionen vom jüdisch-bolschewistischen ,Weltfeind“:

„[...] der unerbittliche Weltjude kämpft für seine Herrschaft über die Völker.“ (Hitler 1934: 738)

Dass er eine bestimmte „Lösung“ für das jüdische Problem favorisierte, ließ Hitler bereits 1920 erkennen, vgl. (46). 13 Jahre vor seiner Machtübernahme war im Programm der NSDAP sowie allen sonstigen Bekundungen die „Judenfrage“ unveränderlich als ideologische Basiskomponente verankert. 1931 prophezeite er dem deutschen Judentum, dass es im Falle einer Auseinandersetzung „,vom Rad der Geschichte [...] zermalmt“ würde (Gespräch Hitler-Breiting Juni 1931, zit. n. Calic 1968: 94 f., vgl. Adam 2003: 27 ff.). Signifikant ist in diesem Zusammenhang die Aussage Gottfried Feders, eines NSDAP-Gründungsmitglieds, zu den weltanschaulichen Grundlagen der NSDAP im Jahre 1920:

„Antisemitismus ist gewissermaßen der gefühlsmäßige Unterbau unserer Bewegung.“ (Feder 1927: 17)

Judenhass war emotionales Dogma des nationalsozialistischen Programms. Das gefühlte Ressentiment wurde als Rassenlehre einerseits zur Wissenschaft und anderseits zum Parteiprogramm erhoben. Antisemitismus wird nach 1933 offiziell zur Staatsdoktrin. Die bislang in der Gesellschaft von Individuen artikulierte Judenfeindschaft wurde nun offiziell auf eine legale Basis gestellt und flächendeckend sowie verbindlich institutionalisiert. Juden aus der Gesellschaft zu entfernen, dieser Gedanke war nicht ökonomisch, sozial oder politisch motiviert, sondern entsprang der ressentimentgeleiteten Ideologie ${ }^{43}$ des NS-Regimes:

43 Partiell kamen im Rahmen dieser ideologisch motivierten Ausrottungspolitik Faktoren wie z. B. Sozialneid auf den ökonomischen Erfolg einzelner jüdischer Bürger hinzu, aber nur die Konzeptualisierung von Juden als Volksschädlingen kann das Ausmaß der Shoah erklären (s. auch Bauer 2001 und 2011). Erklärungsansätze wie zuletzt von Aly (2011) vorgelegt, die sich auf den wirtschaftlich motivierten Antisemitismus konzentrieren (s. hierzu bereits Pulzer 1966: $32 \mathrm{ff}$. und Adam 2003: 85 ff.), erfassen nicht die Relevanz der ideologischen und emotionalen Grundlagen des Judenhasses, sondern reduzieren das Phänomen der Judenfeindschaft auf Komponenten und Begleiterscheinungen, die zwar (insbesondere zu Beginn der Machtübernahme) wichtig, aber nicht zentral waren. Die Motive der Endlösung werden dadurch verkürzt und verzerrt dargestellt. S. hierzu auch kritisch Bauer (2011). Dass Eichmann, trotz 

„Gewiß ist der Jude auch ein Mensch. Noch nie hat das jemand von uns bezweifelt. Aber der Floh ist auch ein Tier - nur kein angenehmes. Da der Floh kein angenehmes Tier ist, haben wir vor uns und unserem Gewis- sen nicht die Pflicht, ihn zu hüten und zu beschützen und ihn gedeihen $\mathrm{zu}$ lassen, sondern ihn unschädlich zu machen. Gleich so ist es mit den Juden.“ (Goebbels 1943: 89)

Antisemitismus wurde entsprechend auf allen kommunikativen Ebenen in der Öffentlichkeit artikuliert. Auf Plakaten, in Zeitungen, an Geschäften, Litfaßsäulen und Häuserwänden waren verbal-aggressive Sprüche mit gewaltandrohenden Aufforderungen, Warnungen, Verfluchungen und Drohungen wie „Deutsche, wehrt euch, kauft nicht bei Juden!“ (Berlin, 1933, vgl. Königseder 2011: 61), „Juda verrecke“ (Berlin, 1933), „Keiner soll hungern, keiner soll frieren, aber die Juden sollen krepieren.“ (Deutschland, 1935, vgl. Améry [1966] 62008: 35) an der Tagesordnung. Alle Massenmedien verbreiteten judenfeindliche Propaganda. Neben den ungezügelten Verbal-Aggressivitäten von Goebbels und den zahlreichen Hass- und Polemik-Attacken diverser Gauleiter, die sich in Gewaltandrohungen gegen Juden ergingen, wurden vor allem im Stürmer ab 1934 wöchentlich vulgäre, hasserfüllte Brachialverbalismen, in denen Tier- und Krankheitslexik dominant waren, verbreitet. Die Schaukästen dieses antisemitischen Hetzblattes wurden in allen Gegenden Deutschlands aufgestellt. Schon 1933 hatte man zudem begonnen, judenfeindliche Parolen gesetzlich zu normieren (z. B. in Form von Berufsverboten). Terror und Gewalt wurden zunehmend von der Staatsbürokratie legalisiert.

Alle Verbalisierungsformen in der NS-Zeit spiegeln die konzeptuelle und emotionale Entwertung von Juden und Judentum wider und lassen semantische Konstanten der judeophoben Diffamierung wie Delegitimierung, Dämonisierung und Dehumanisierung erkennen (s. hierzu Kap. 6).

Die Konzeptualisierung von Juden als WELTüBEL war das Fundament für den eliminatorischen Antisemitismus der Nationalsozialisten, welcher im Rahmen des geschlossenen ideologischen Weltbildes und seiner immanenten irrealen „Logik“ zur „Endlösung“ führte. Von den Nürnberger Rassegesetzen über die öffentliche Stigmatisierung, die Ausgrenzung aus allen Bereichen des normalen Lebens, die Aberkennung aller Rechte und die Verweigerung von Humanität bis zu den Gaskammern führte ein kontinuierlicher, ideologisch homogener und bürokratisch

Knappheit der Ressourcen, in den Kriegsjahren die dringend für Kriegsaktivitäten benötigten Eisenbahnwaggons für die „Endlösung“ stets erhielt, zeigt, dass der ideologische Hass und sein Programm der Auslöschung über ökonomischen und militärischen Interessen standen (s. Friedländer 2006: 647). 
perfektionierter Weg. ${ }^{44}$ Minutiös war in den Rassegesetzen „zum Schutze des deutschen Blutes“ niedergelegt, wer „Voll-, Dreiviertel-, Halb- oder Vierteljude“ sei. Bis in kleinste Details sich ergehende Paragraphen regelten die „Sortierung“ dieser so Klassifizierten sowie deren Verwandter und Kinder. Himmler forderte auf der Basis dieser Gesetzgebung u. a. „für Mischlinge 2. Grades“ ein „Verfahren [...] wie man es bei einer Hochzucht bei [...] Tieren anwendet“" und „im Falle der [...] Minderwertigkeit“ die Sterilisation (s. Adam 2003: 328).

Das Protokoll der Wannseekonferenz, die der Absprache zur Umsetzung der Endlösung diente, liest sich wie ein Text einer Schädlingsbekämpfungsfirma, die bürokratisch und völlig emotionslos Hygiene- und Eliminierungsregeln für die Beseitigung von Abfall und Unrat niederschreibt. Dass in diesem Fall der als Schädlingsbefall klassifizierte und in Zahlenkolonnen erfasste „Unrat“ Menschen waren, wurde ausgeblendet. Die Radikalität der „Endlösung“ entsprach der Geschlossenheit der Weltanschauung. Die „Endlösung“ entsprach der kausalen „Begründung“, Juden, obgleich diese höchst produktiv und voll integriert im deutschen Wirtschafts-, Wissenschafts- und Kunstleben wirkten und keinerlei Gefahr, sondern im Gegenteil eine Bereicherung darstellten, zum Wohle der Menschheit auszulöschen. Als ein drastisches Beispiel, das diese „Realität“ transparent macht, können die Worte des SS-Reichsführers Heinrich Himmler im Oktober 1943 betrachtet werden. Himmler sagte in einer geheimen Rede vor hohen SS-Offizieren:

„Ich will hier vor Ihnen in aller Offenheit auch ein ganz schweres Kapitel erwähnen [...] Ich meine jetzt die Judenevakuierung, die Ausrottung des jüdischen Volkes [...] Dies ist ein [...] Ruhmesblatt unserer Geschichte [...] Wir hatten das moralische Recht, wir hatten die Pflicht gegenüber unserem Volk, dieses Volk, das uns umbringen wollte, umzubringen.“

(Himmler am 4. Oktober 1943; s. Smith/Peterson 1974: 203)

Es bestand nach Himmler die moralische Pflicht, die Juden auszurotten. Wir machen es uns zu leicht, wenn wir Goebbels oder Himmler mit unserem modernen Bewusstsein als geistig verwirrt abstempeln. Sie waren es nicht im System der NS-Ideologie, und sie wurden auch von ihrer Umgebung nicht so gesehen. Sie selbst waren persönlich davon überzeugt, das Richtige $\mathrm{zu}$ tun. ${ }^{45}$

44 Vgl. hierzu u. a. Longerich (1998) und Browning (2003).

45 Das Ressentiment basiert auf dem Glauben, dass die Menschen richtig und wahrhaftig handeln und sich gegen das Böse, das Übel, das prinzipiell Andere in der Gestalt minderwertiger oder Schaden zufügender anderer Menschen wehren müssen. 

„Ich glaube, meine Herren, daß Sie mich so weit kennen, daß ich kein blutrünstiger Mensch bin und kein Mann, der an irgendetwas Hartem, was er tun muß, Freude oder Spaß hat. Ich habe aber andererseits so gute Nerven und ein so großes Pflichtbewußtsein - das darf ich für mich in Anspruch nehmen -, daß ich dann, wenn ich eine Sache als notwendig erkenne, sie kompromißlos durchfahre.“ (Himmler am 24. Mai 1944; s. Smith/Peterson 1974: 206)

In diesem Fall handelte es sich um die Ermordung der jüdischen Frauen und Kinder. Sie mussten nach Himmlers Verständnis umgebracht werden, sonst würden ,in den Kindern die Rächer groß werden [...] die dann unsere Kinder und unsere Enkel umbringen“. Die für uns heute unvorstellbare Gefühlskälte, die absolute Mitleidlosigkeit und Inhumanität ist mit einem geschlossenen anti-jüdischen Weltbild, einem monströsen Phantasiekonstrukt mit langer Tradition verbunden und nur durch dieses erklärbar (s. hierzu auch Bauer 2001; s. Kap. 9.3.1). Hierin liegt das Unikale, dass Juden als Juden ausgerottet wurden, ohne dass ökonomische, soziale oder politische Gründe dies hätten rechtfertigen können. Der „Erlösungsgedanke“ stand im Nationalsozialismus im Vordergrund: die Welt von der Existenz der Juden zu befreien. Hitler behielt seine Wahnvorstellungen ungebrochen bis zu seinem Ende bei:
„Vor allem verpflichte ich die Führung der Nation und die Gefolgschaft zur peinlichen Einhaltung der Rassegesetze und zum unbarmherzigen Widerstand gegen den Weltvergifter aller Völker, das internationale Judentum. Berlin, 29. April 1945“
(Adolf Hitlers Testament, Hitler 1945: 10)

Wir sind heute durch die abstrakt gehaltene Semantik der Bewertungsreflexion im wissenschaftlichen und gesellschaftlichen Diskurs über die NS-Zeit an Ausdrücke und Phrasen wie Brutalität, Inhumanität, jüdische Opfer der rassistischen NS-Politik, Verbrechen der Nazis etc. gewöhnt. Doch dieser entpersonalisierende Sprachgebrauch lässt im Bewusstsein und im Gefühl aufgrund seiner Entkonkretisierung nicht die Dimension des Zivilisationsbruchs, nicht die Ungeheuerlichkeit der monströsen Realpolitik fassbar werden. Man muss sich bildhaft und konkret vor Augen führen, was zwischen 1933 und 1945 geschah: Ein Teil der Mitmenschen in Deutschland wurde zum Volksfeind und -schädling erklärt, all seiner Rechte beraubt, durch die Nürnberger Rassegesetze offiziell und im Rahmen des Gesetzes als minderwertige Kreaturen deklariert und schließlich in Viehwaggons zur Ermordung gefahren. All diese Aktivitäten wurden mit großer Sorgfalt und Präzision, mit viel bürokratischem Aufwand und rationaler Überle- 
gung durchgeführt. Diese bürokratische Effizienz, getragen von allen wesentlichen Organisationsstrukturen Deutschlands, ließ am Ende sechs Millionen jüdische Menschen verschwinden bzw. ipsis litteris in Rauch auflösen.

\subsection{Judenfeindschaft nach 1945: Marginalisierung des Zivilisationsbruchs und Empathieverweigerung}

Es kam nach 1945, als das Ausmaß der Verbrechen an den Juden weithin bekannt und deutlich wurde, keineswegs zu dem tiefgreifenden Wandel im kollektiven Bewusstsein, den dieser Zivilisationsbruch hätte einleiten müssen. Zwar wurden die judenfeindlichen Bilder und Texte offiziell verbannt, ihre Reproduktion öffentlich sanktioniert und tabuisiert, doch eine wirklich tiefgreifende Reflexion, eine kritische Aufarbeitung der Gründe und Motive für den Hass und die Ausrottungspolitik gab es nicht (flächendeckend). ${ }^{46}$ Vielmehr wurde der Holocaust zumeist als das Ergebnis der Besessenheit einiger weniger Nationalsozialisten dargestellt und somit entscheidend fehlinterpretiert, das Bewusstsein für die Dimensionen der Judenfeindschaft wurde nicht entwickelt. Dass Judenfeindschaft in nahezu allen Schichten der Gesellschaft als ein integraler Teil der viel beschworenen abendländischen Denkstrukturen ${ }^{47}$ seit Jahrhunderten zum kulturellen Allgemeingut gehörte, wurde weder von den institutionellen Eliten noch von der Bevölkerung hinreichend erörtert und damit die Chance verpasst, ein wirkliches Umdenken einzuleiten. Was jahrhundertelang tradiert worden war, ließ sich durch die vereinzelten und halbherzigen Versuche nicht in wenigen Jahren aus dem kollektiven Bewusstsein streichen bzw. aus dem Sprachgebrauch entfernen (zum Nachkriegsantisemitismus vgl. auch Stern 1991a, b und 1993).

Sowohl die fundierten geschichtswissenschaftlichen Analysen von Wolgast (2001) als auch die umfassenden linguistisch-diskursanalytischen Untersuchungen von Kämper (2005 und 2007) belegen unabhängig voneinander, dass keine

46 Erst Ende der 1960er Jahre (also über 20 Jahre nach dem Zusammenbruch des NS-Regimes) kam es im Zuge der Auschwitzprozesse und der studentischen Protestaktionen zu nachhaltigen Diskussionen und gesamtgesellschaftlichen Aufarbeitungen (vgl. Frei 2005). Doch noch bis in die späten 1980er Jahre zeichneten sich geschichtswissenschaftliche Abhandlungen zur NSZeit durch die Marginalisierung des Massenmordes an den Juden aus (s. Herbert 1998: 15). Und die Opferperspektive wurde umfassend erst durch Friedländer (2006) in den Fokus historischer Forschung gerückt.

47 Der Verweis auf die abendländische christliche Kultur gehörte in der Nachkriegszeit kontinuierlich zum Repertoire des öffentlichen Diskurses, ohne dass es zu einem kritischen Hinterfragen der dunklen Seiten dieser Kultur kam. Es gibt sprachlich-diskursiv keinen Hinweis für das Bewusstsein einer Umbruchsituation (s. Kämper 2005). 
intensive und flächendeckende Aufarbeitung der antisemitischen NS-Taten in den Trägerinstitutionen stattfand. Stattdessen praktizierten die Mitglieder von Hochschulen, Parteien und Kirchen bereits 1945/1946 eine Relativierungs- und Schuldabwehrkommunikation. Anhand der Analysen von universitären Reden, Hirtenbriefen und programmatischen Texten aus der Politik wird deutlich, dass zwar das nationalsozialistische Gewaltregime übereinstimmend abgelehnt und verurteilt wurde, zugleich aber die Auseinandersetzung mit dem Antisemitismus unterblieb und sich die Wahrnehmung des Holocausts durch Marginalisierung auszeichnete. In den Hirtenbriefen der deutschen Bischöfe im Sommer 1945 wurde beispielsweise die Judenermordung gar nicht erwähnt (s. Wolgast 2001: 188). Im Fuldaer Hirtenbrief vom 23.08.1945 wurden die Verbrechen zwar angesprochen, die Juden aber gemäß der rassistischen Ideologie als „Nichtarier“ und „Volksgenossen fremden Stammes“ bezeichnet (Wolgast 2001: 191). Die Hirtenbriefe des Freiburger Erzbischofs Gröber sind typisch für die Marginalisierungs- und DeRealisierungsprozesse der unmittelbaren Nachkriegszeit auf Seiten der katholischen Kirche: Als Träger des NS-Regimes wurden Ausnahmepersonen genannt wie „Phantasten“ und „kurzsichtige Nationalisten“(s. Amtsblatt Freiburg, Jg. 1945, 8, 41 f., zit. n. Wolgast 2001: 197). Als Opfer nannte Gröber - neben vielen anderen - „Menschen fremder Rasse“. Diese Sprachgebrauchspraxis deckt die ungebrochene Macht des rassistisch-völkischen Antisemitismus und die Habitualisierung der dazugehörigen Lexik auf. Auch von Seiten der evangelischen Kirche wurde das Thema des Judenmordes eher zögerlich behandelt. Sie hatte die Machtübernahme 1933 euphorisch begrüßt und fand nach dem Zusammenbruch nicht die notwendige Distanzierung vom Antisemitismus (s. Wolgast 2001: 226). Ähnlich sah es bei Politikern und Akademikern aus: Die Reden der Universitätsrektoren ließen nach 1945 keine grundlegende Läuterung oder Selbstkritik erkennen. Den wissenschaftlichen Kriterien von Aufklärung, Wahrhaftigkeit und Objektivität wurden sie in keiner Weise gerecht (s. Wolgast 2001: 328 ff.); auf die Gründe von Judenhass und Judenmord gingen sie nicht ein. So bleibt zu konstatieren, dass es keine umfassende, ernsthafte oder gar aufrüttelnde Auseinandersetzung mit der nationalsozialistischen Ideologie der Judenfeindschaft, ihrer tiefen Einbettung in der abendländischen Kultur und den wesentlichen Ursachen des Holocausts gab. Stattdessen zeichneten sich die Eliteinstitutionen Deutschlands durch Minimierung der eigenen Schuld und Verantwortung bei gleichzeitiger Maximierung der Schuldzuweisung auf die Gruppe der Nationalsozialisten sowie das durch keinen Zweifel getrübte Bekenntnis zu überlieferten Werten aus. Verdrängung, Umdeutung und Marginalisierung waren die vorherrschenden Tendenzen im Umgang mit der Judenvernichtung.

Wie in Deutschland nach dem Krieg über den Nationalsozialismus und seine Verbrechen gesprochen wurde, hat Kämper (2005) diskursanalytisch untersucht. 
Auch ihren Ergebnissen zufolge gab es keine grundlegende Auseinandersetzung mit der Vergangenheit, keinen kritischen Blick auf Gegenwart und Zukunft. Statt Aufarbeitung und Neubesinnung fanden Prozesse der Verdrängung ${ }^{48}$ und Marginalisierung statt.

\begin{abstract}
„Schuldabwehr und Rechtfertigung sind kommunikative Akte, mit denen nach 1945 eine ganze Nation identifiziert wurde und die zu nationalen Stereotypen gerieten, welche bis heute Gültigkeit haben. Entsprechend sind die argumentative Ausgestaltung und die lexikalische Umsetzung des Abwehr- und Rechtfertigungsdiskurses mit den hier rekonstruierten Argumentationshandlungen 'Umdeuten', 'Marginalisieren-Idealisieren-Egalisieren', 'Gegenklage' und den sie repräsentierenden Registern (Irrtum, Glaube, dienen/Dienst, Pflicht, machtlos, nicht gewusst, Befehl etc.) als diesen Abwehrdiskurs begründende Konstituenten der deutschen Sprachgeschichte zu bewerten.“ (Kämper 2005: 496 f.)
\end{abstract}

Der Schuld- bzw. Identitätsdiskurs der unmittelbaren Nachkriegszeit zeichnete sich zudem dadurch aus, dass ohne tiefgreifende Skepsis erneut die tradierten Werte des Abendlandes beschworen wurden, obgleich doch diese in sich den alten Judenhass bewahrten und pflegten.

Dass Antisemitismus als kulturelles Phänomen, als geschichtliche Erscheinung, als abendländisches Erbe seit Jahrhunderten kollektiv über alle Kommunikationsstrukturen als Glaubenssystem vermittelt worden war (vgl. Volkov 1990, 2000, 2006), wurde ignoriert. Stattdessen betonte man bereits unmittelbar nach Kriegsende die Singularität der Judenverfolgung als spezifische Charakteristik der nationalsozialistischen Gewaltpolitik und Rassismus-Ideologie. ${ }^{49}$

Entsprechend war die Realpolitik an den Kriterien des Wiederaufbaus und der Zukunftsorientiertheit ausgerichtet. Trotz der sogenannten Entnazifizierungen gelangten ehemalige Nazi-Funktionäre oft mühelos in hohe und verantwortliche Positionen in Politik, Wirtschaft und Kultur (s. Frei 1997). Der Aufbau des

48 Die Mitscherlichs haben in ihrer einflussreichen Analyse gezeigt, inwiefern diese Verdrängungsprozesse maßgeblich dafür verantwortlich waren, dass unter den Deutschen nicht nur „die Unfähigkeit zu trauern“ zu konstatieren war, sondern auch die Unfähigkeit, Empathie für die Opfer zu empfinden (s. hierzu Mitscherlich/Mitscherlich 1967; s. hierzu auch Kap. 9.3.1).

49 Bis heute hält sich zum Teil die Vorstellung, der virulente Antisemitismus sei nur von wenigen, besessenen Nazis getragen und ausgeführt worden. Der Historikerstreit in den 1980er Jahren ließ transparent werden, wie groß auch in der akademischen Elite Deutschlands das Bedürfnis nach Relativierung der nationalsozialistischen Verbrechen war (s. hierzu Augstein 41987, Evans 1991). Goldhagen, der mit seinem Buch Hitlers willige Vollstrecker (1996) mit dieser Vorstellung brach und zeigte, wie weit verbreitet der Judenhass von vielen Deutschen geteilt wurde, stieß auf vehementen Widerstand. Die Debatte um seine Thesen ist daher von hoher Emotionalität geprägt und die zum Teil durchaus berechtigte Kritik an seinem methodischen Vorgehen wird oft von irrational polemischen Tönen überlagert. 
kriegszerstörten Landes hatte Priorität, ein rückwärtsbezogener Blick war weder im Sinne der politischen Funktionsträger noch der Bevölkerung. Die grundlegende Zäsur, die der Holocaust aufgrund seiner unikalen Monstrosität hätte einleiten müssen, blieb damit sowohl kognitiv als auch emotional aus.

Nicht die Gefühle von Entsetzen, Schande und Scham waren vorherrschend, nicht das Mitleid mit den Opfern und den Überlebenden der Vernichtungslager, sondern vielmehr Selbstmitleid und die zukunftsgewandte Hoffnung auf ein besseres Leben. Peinliches Schweigen und Desinteresse sowie Abwehr und Gleichgültigkeit prägten emotional die Einstellung gegenüber den toten und lebenden Juden. Als exemplarisch für diese Haltung ist der folgende Text zu betrachten:
„Kein Schwerkranker wird sich auf dem Krankenbett damit beschäfti- gen, Fieberkurven zu studieren, und es ist durchaus begreiflich, daß in dem Deutschland von 1947, wo der Hunger und die Kälte nahe Nachbarn geworden sind, die KZ-Literatur keine große Anhängerschaft gewinnen kann. Hatten die Häftlinge Hunger? Den haben wir auch. Haben die Häft- linge gefroren? Das tun wir auch. Häuften sich die Toten vor den Krema- torien? Wenn es so weitergeht, werden sie das bald wieder tun. Waren die Häftlinge eingesperrt? Das sind Tausende von Kriegsgefangenen auch.“ (Borchert [1947] 2009: 503)

Die Aussagen des hochgelobten Nachkriegsschriftstellers Wolfgang Borchert, der in seinen Dramen und Erzählungen das Leid der Nachkriegsdeutschen in den Mittelpunkt rückte und kein Wort der Empathie für die jüdischen Opfer des deutschen Massenmords findet, geben Einblick in die vorherrschende Einstellungsstruktur unter den Deutschen. Die Verbrechen an den Juden werden durch Verschweigen relativiert, ihr Leid wird auf eine Ebene mit den Entbehrungen der Menschen in Nachkriegsdeutschland gehoben und damit seiner alle Grenzen der Humanität sprengenden Dimension ${ }^{50}$ beraubt. Die Gleichsetzung der durch Krieg und Gewaltherrschaft hervorgerufenen Konsequenzen mit der systematischen Ausrottung belegt den Mangel an kritischem Bewusstsein und Bereitschaft, Empathie zu entwickeln. Die Äquivalenzsetzung ${ }^{51}$ der beiden eigentlich nicht zu vergleichenden Leid-Dimensionen ermöglicht es zudem, sich der erdrückenden

50 Dieses Empfinden ist die emotionale Basis der aktuellen Strategie der Schuldabwehr (s. Kap. 9.3.2). Der Holocaust wird mit eigenem Leid aufgerechnet; wie in (53) wird dabei argumentiert, die Deutschen hätten durch den Zweiten Weltkrieg ähnlich oder genauso gelitten, für dieses Leid gebe es aber kein übertriebenes Gedenken.

51 Ein ähnliches Muster findet sich aktuell in der Gleichsetzung und Aufrechnung von NSGewalt und israelischen Militäraktionen beim Anti-Israelismus (s. Kap. 7.2.2). 
Last und moralischen Verantwortung zu entziehen (was sich bis zum heutigen Tag bei einigen Menschen in Deutschland beobachten lässt).

Der nach 1945 bis in die späten 1960er Jahre im Alltagsdiskurs viel artikulierte Ausspruch „Unter Hitler hätt’s das nicht gegeben!“ ist signifikant, da er geradezu prototypisch als Sprachgebrauchsmuster Aufschluss über (zum Teil durchaus unbewusste) Marginalisierungstendenzen gibt. Durch Hervorhebung der positiven Kontrollfunktion des NS-Regimes wird gleichzeitig die Dimension des Völkermords ausgeblendet, seine Relevanz minimiert. Dieser noch Jahrzehnte nach dem Zusammenbruch des NS-Regimes in Alltagsgesprächen benutzte Floskelsatz ist daher symptomatisch für den Umgang mancher Deutschen mit dem Holocaust. Er fokussiert die als positiv memorierten Eigenschaften ${ }^{52}$ der NS-Politik (Kriminalitätsbekämpfung; die konservative Vorstellung, die sich in der Floskel Zucht und Ordnung artikuliert). Als Implikatur ergibt sich die Relativierung der Verbrechen an den Juden: Das Ausmaß des Judenmordes steht hinter dem Erfolg Hitlers zurück, denn sonst würde der Erfolg nicht erwähnenswert sein.

Auf rechtsextremistischen und neonazistischen Homepages ist diese Floskel daher bis heute zu finden (vgl. z. B. die erst 2012 geschlossene rechtsextremistische Plattform thiazi.net mit ihrer Rubrik Sprüche von Mama und Papa).

Um Trauer und Schmerz zu empfinden, um Empathie zu entwickeln, hätte es der Einsicht bedurft, dass ein integraler, höchst vitaler Teil der Gesellschaft isoliert und vernichtet worden war (keineswegs also eine (als fremd und undeutsch klassifizierte) externe Gruppe). Da aber diese Identifikationsbasis nicht vorhanden war und auch nicht evoziert wurde, kam es zur „Unfähigkeit zu trauern“ (s. Mitscherlich/Mitscherlich 1967) bzw. sich zu schämen. Die offizielle Scham- und Verantwortungsmoral wurde von vielen Deutschen als oktroyiert empfunden. Auf diesen Emotionen der Abwehr entwickelte sich ein Nachkriegsantisemitismus, den der jüdische Psychoanalytiker Zvi Rex (zit. n. Heinsohn 1988: 115) treffend formulierte: „Auschwitz werden uns die Deutschen niemals verzeihen!“

Konstitutiv für den Nachkriegsantisemitismus sind das Relativieren oder Leugnen der Schuld von Deutschen am Völkermord sowie die Projektion der Schuld auf die Juden: eine moderne Variante der Täter-Opfer-Umkehr.

52 Bei einer 2011 durchgeführten Umfrage vom Institut für Jugendkulturforschung unter 16- bis 19-jährigen in Wien lebenden Jugendlichen zeigte sich eine Zustimmungsrate von 11,2 Prozent zu der Aussage „Adolf Hitler hat für die Menschen auch viel Gutes getan“. Über 18 Prozent bejahten „Die Juden haben nach wie vor zu viel Einfluss auf die Weltwirtschaft“. Ähnliche Einschätzungen existieren auch in Deutschland. Auf einer Pressekonferenz vom 06.09.2007 äußerte sich z. B. die ehemalige Nachrichtensprecherin Eva Herrmann positiv zum Mutter-Konzept während des Nationalsozialismus, und argumentierte in der Talkshow Kerner vom 10.10.2007 - konfrontiert mit ihrer Verwendung des Ausdrucks Gleichschaltung -, dass außerdem die in der NS-Zeit gebauten Autobahnen bis zum heutigen Tage verwendet werden. 
Dieser Schuldabwehr-Antisemitismus wird in der Forschungsliteratur oft als Antisemitismus „nicht trotz, sondern gerade wegen Auschwitz“ charakterisiert (s. hierzu Benz 2001: 55). Tatsächlich aber sind beide Dimensionen wichtig, um den Nachkriegsantisemitismus zu verstehen. Trotz der Erfahrung Auschwitz kam es bei vielen Deutschen zu keiner grundlegenden Veränderung in ihrer Einstellung zu den Juden (so dass die tradierten Klischees weiter im persönlichen Alltagsdiskurs bedient wurden) und wegen Auschwitz entwickelten sich zusätzliche auf Verantwortungsleugnung und Schamverdrängung basierende Stereotype und zwar vor allem die von JUDEN ALS STÖRENFRIEDE UND LÄSTIGE MAHNER SOwie JUDEN ALS HOLOCAUSTAUSBEUTER UND (MEINUNGSDIKTAT-)ERPRESSER. Sie sind übrigens keineswegs als sekundär ${ }^{53} \mathrm{zu}$ bezeichnen, da sie auf tradierten judenfeindlichen Konzeptualisierungen basieren und diese lediglich auf die aktuelle Situation beziehen und entsprechend modifizieren bzw. elaborieren (was seit Jahrhunderten kennzeichnend für die Transformationen judenfeindlicher Vorstellungen und Artikulationsformen ist).

Dass Juden angeblich die Erinnerung an den Holocaust ausbeuten und als Sozialschmarotzer agieren, indem sie finanzielle Forderungen an die Bundesrepublik Deutschland stellen, entspricht der tradierten Konzeptualisierung von Juden als GIERIGEN PARASITEN UND volKSSCHÄDLINGEN. Das Stereotyp, dass sie als LÄSTIGE, UNVERSÖHNLICHE UND RACHSÜCHTIGE MAHNER auftreten, ist eine moderne Variante der bereits im Mittelalter kursierenden Vorstellung von Juden als Störenfrieden und basiert zudem auf der Konzeptualisierung, Juden seien keine Deutschen. Die Holocaustleugnung mit der Verschwörungskomponente, Juden hätten die Vernichtung ihres Volkes erfunden, um die Welt moralisch unter Druck zu setzen und finanziell zu erpressen, korreliert mit der Attribuierung, Juden seien Lügner und ist geknüpft an das Stereotyp des RAFFGIERIGEN SCHACHERERS UND GELDMENSCHEN. Die judenfeindlichen Konzepte bleiben bestehen, aber die Ausdrucksformen verändern und modifizieren sich, passen sich aktu-

53 In der (deutschsprachigen) Antisemitismusforschung spricht man nach dem Jahr 1945 vom sekundären Antisemitismus (s. Benz 2004: 19 ff., Bergmann ${ }^{3} 2006$ ). Der Terminus geht auf Peter Schönbach, einen Mitarbeiter Adornos zurück (s. Adorno [1962] 1971: 107 f.). Wir schließen uns der Terminologie der deutschsprachigen Forschung, die zwischen primärem (auch als „klassischer Antisemitismus“ beschrieben, Heyder et al. 2005: 147) und sekundärem Antisemitismus unterscheidet, jedoch nicht an. Der Begriff „sekundärer Antisemitismus“ ist irreführend, da seine Bedeutung suggeriert, es handele sich um einen zweitrangigen, abgeleiteten, eventuell weniger virulenten Judenhass. Dies ist aber nicht der Fall. Wir plädieren daher ausdrücklich dafür, dass zukünftig die inadäquaten Bezeichnungen primär und sekundär nicht mehr benutzt werden sollen. Sekundär ist der Nachkriegsantisemitismus in keiner Weise: Er ist weder abgeleitet oder verändert, noch weniger virulent. 
ellen sozialen und politischen Gegebenheiten an (vgl. auch Bergmann 2001: 38, Simmel [1946] 2002a: 12, von Braun 2004: 11, Kreis 2005: 21).

Eine für die vorliegende Untersuchung sehr wichtige Veränderung gab es nach 1945 jedoch: Die über Jahrhunderte hinweg praktizierte offene und öffentliche Artikulation antisemitischen Gedankenguts wurde nach Kriegsende unterbunden. Die Kommunizierbarkeit von Verbal-Antisemitismen erfuhr so eine Einschränkung; das Sagbarkeitsfeld für Judenfeindlichkeit wurde verkleinert und als Diskursform aus dem öffentlichen Kommunikationsraum in den privaten Bereich $^{54}$ verschoben. Dies zog aber nicht mit sich, dass judenfeindliche Einstellungsrepräsentationen und stereotype Konzeptualisierungen auch verschwanden.

„Vielmehr sind antijüdische Stereotype in der demokratischen, etablierten Öffentlichkeit heute quer durch die politischen Lager und durch unterschiedliche Akteure verbreiteter als noch vor Jahren.“ (Rensmann 2004: 487)

Die gesetzliche ${ }^{55}$ und gesellschaftliche Tabuisierung bzw. Sanktionierung eines expliziten Antisemitismus führte stattdessen zu neuen Kommunikationsformen. Judenfeindliche Inhalte wurden und werden (mit Ausnahme von rechtsextremistischen Kreisen) als indirekte Sprechakte vermittelt (und als „Umwegkommunikation“ realisiert; ${ }^{56}$ vgl. u. a. Rensmann 2004 sowie Bergmann/Heitmeyer 2005a, b; s. Kap. 3).

Während sich zudem bis 1945 Antisemiten auch selber ganz unverhohlen und selbstverständlich als solche bezeichneten, ist dies nach den Verbrechen des Holocausts nicht mehr der Fall. Heute bezeichnen sich Menschen, die judenfeindliche Meinungen vertreten, als „kritische Denker“ oder „Friedensaktivisten“,

54 Diese Verschiebung vom Öffentlichen ins Private bezeichnen Bergmann und Erb (erstmals 1986) als „Kommunikationslatenz“, wobei Latenz nicht wie im kognitionslinguistischen Sinne auf unbewusste Konzeptualisierungen, sondern auf die Veränderung der Öffentlichkeitsebene und später dann auch der Äußerungsform verweist. Der Begriff der Kommunikationslatenz, der heute von vielen Autoren, die ihn benutzen, oft uneinheitlich verwendet wird, gibt in seiner ursprünglichen Lesart an, dass sich der Ausdruck judenfeindlicher Parolen von der öffentlichen zur privaten Diskursebene verschob (vgl. Benz 2004: 19 f., Bergmann ${ }^{32006: 117 ~ f .) . ~}$

55 Der Paragraph der Volksverhetzung wurde in das Grundgesetz der Bundesrepublik Deutschland u. a. aufgenommen, um einen diskriminierenden Sprachgebrauch zu verhindern, der zum einen Menschen in ihrer Würde herabsetzt, beleidigt und verletzt und zum anderen die Basis für Vorurteile, Hass und Gewalt darstellen und schaffen kann.

56 Eine umfangreiche Erfassung, präzise Analyse und genaue Beschreibung der diversen Typen dieser neuen Ausdrucksvarianten hat bislang keiner der (politik- oder sozialwissenschaftlich ausgerichteten) Autoren vorgenommen. Dies ist daher ein wichtiges und innovatives Anliegen dieses Buches. 
die „im Namen von Gerechtigkeit und Menschenrechten“ und aus „Sorge um den Weltfrieden“ sprechen. Diesen scheinbar nicht-fanatischen und nicht-rassistischen Alltagsantisemitismus charakterisiert Marin (1979/2000) - bis heute zutreffend - als „Antisemitismus ohne Antisemiten“ (s. hierzu auch Améry 1969/1971 zum „ehrbaren Antisemitismus“ sowie Schwarz-Friesel 2010a zum „legitimen Antisemitismus").

Für die folgenden Betrachtungen der aktuellen judenfeindlichen Sprachgebrauchsmuster und Kommunikationsprozesse ist dies insofern von entscheidender Bedeutung, als die heutigen Ausdrucksformen des Antisemitismus primär implizit und/oder über die Formvariante des Anti-Israelismus, die als „IsraelKritik“ deklariert wird, (auch vermehrt öffentlich) realisiert werden (s. Kap. 7). Dadurch wird der kommunikative Raum für Verbal-Antisemitismen in der Gesellschaft wieder größer.

\subsection{Aktuelle Judenfeindschaft: Zur Diskussion um den „neuen“ Antisemitismus im 21. Jahrhundert}

Seit einigen Jahren wird in der Antisemitismusforschung darüber diskutiert, ob bestimmte Veränderungen in der öffentlichen Kommunikation, (die weltweit steigende Anzahl von) Gewalttaten gegenüber jüdischen Einrichtungen und Tendenzen bei der massenmedialen Berichterstattung über Israel sowie bestimmte Typen der Kritik an Israel es erfordern, von einem „neuen Antisemitismus“ im 21. Jahrhundert ${ }^{57} \mathrm{zu}$ sprechen (vgl. hierzu z. B. die Diskussion in Naumann 2002, Rabinovici et al. 2004; s. auch Kaufmann/Orlowski 2002, Nonn 2008: $101 \mathrm{ff}$. und Schwarz-Friesel et al. 2010: $2 \mathrm{ff}$.). Dabei hat u. a. die Diskrepanz zwischen bestimmten demoskopischen Befragungsergebnissen und den Analysen öffentlicher Diskurse sowie der Anstieg antisemitisch motivierter Gewalttaten ${ }^{58}$ die Debatte angefacht.

57 Der Begriff „neuer Antisemitismus“ wird bereits von Marrus (1986) verwendet, womit dieser eine neu motivierte, gegen Israel gerichtete Feindschaft bezeichnet. Taguieff (2002: 196) konstatiert eine antisemitische Welle in den Jahren 1998 bis 2002 und spricht von einer mehrheitlich von muslimisch geprägten Immigranten getragenen „nouvelle Judéophobie“. Es werde eine Verteufelung Israels betrieben, die zugleich alles als jüdisch Wahrgenommene trifft. Als ideologische Grundlage sieht Taguieff den Antizionismus der Linken. Vgl. auch Gessler (2004).

58 So verzeichnet das Stephen Roth Institute (2010) einen weltweiten Anstieg antisemitischer Gewaltakte seit 2001 bis zu einem extremen Hoch im Jahr 2009. S. auch BMI (2011). Anti-IsraelDemonstrationen mit Hassparolen auf Plakaten sowie weltweite Boykottforderungen und antisemitische Internet-Aktivitäten verstärken den Eindruck einer an Virulenz zunehmenden 
Dass sich bei der aktuellen Judenfeindschaft Veränderungen zeigen, ist dabei unumstritten, doch die Einordnung sowie Bewertung dieser Phänomene und ihrer Auswirkungen wird unterschiedlich vorgenommen: Für einige Wissenschaftler(innen) handelt es sich um zeitgemäße Erscheinungsformen der alten judeophoben Muster mit einer konstanten Semantik und damit also um eine Variante des Nachkriegsantisemitismus, für andere zeigt sich ein qualitativ (und quantitativ) neues Phänomen der Judenfeindschaft, das die Grundlage für die Ausbreitung in der Mehrheitsgesellschaft darstellt (bzw. darstellen könnte).

Als wesentlichen Unterschied zwischen altem und neuem Antisemitismus sehen Rabinovici et al. (2004:8), dass bisherige Muster der Vergangenheitsbewältigung, deren Schwerpunkt die nationalsozialistische Vergangenheit und der Holocaust bildeten, nun nicht mehr griffen. ${ }^{59}$ Im Zentrum stehe jetzt die problematische Gegenwart des Nahostkonflikts und somit die in Frage gestellte Legitimität des Staates Israel als der politischen Form jüdischer Souveränität (vgl. Rabinovici et al. 2004: 8). Zugleich spielen für Rabinovici (2006: 247) die globalen Verflechtungen von europäischem und arabischem Antisemitismus ${ }^{60}$ eine wesentliche Rolle, denn:

Feindseligkeit. Bergmann (2008: 476-479) sieht dagegen auf der Ebene der demoskopisch eruierten Einstellungen keinen längerfristigen negativen Trend und den Anstieg feindseliger Aussagen in den Jahren 1998 bis 2003 als Folge eines „normalen“ Periodeneffekts (vgl. dazu Whine 2006; s. auch EUMC 2004: 319, FRA 2009: 23). Wir haben aber bereits in Kap. 2 erörtert, inwiefern Umfragen als empirische Methoden nur sehr begrenzt in der Lage sind, judenfeindliche Einstellungen mit ihren mentalen und emotionalen Komponenten zu erfassen. 59 Wir werden aber zeigen, dass die aktuelle judenfeindliche Argumentation sich größtenteils durch die Verbindung von vergangenheitsbezogener Schuldabwehr und gegenwartsbezogener Schuldkonstruktion (mittels Täter-Opfer-Umkehr-Strategien) auszeichnet.

60 Dass radikale Islamisten als Träger des aktuellen Antisemitismus fungieren, die sich die alten antisemitischen Konzepte angeeignet haben und mit diesen weltweit anti-jüdische Einstellungen, Vorbehalte und Feindbilder bedienen, sehen auch Benz/Wetzel (2007: 12). Als zentrale Kennzeichen des arabischen Antisemitismus eruierte das Middle East Media Research Institute (MEMRI) aufgrund arabischer Medienanalysen zum einen das Vorhandensein antijüdischer Meinungen, die von traditionellen islamischen Quellen abgeleitet werden, sowie christlich und rassistisch motivierter, aus Europa stammender antisemitischer Stereotype, Bilder und Beschuldigungen. Zum anderen sind Holocaustleugnung, Gleichsetzung von Zionismus mit Nationalsozialismus sowie die Aberkennung des Existenzrechts Israels Charakteristika des arabischen Antisemitismus (s. Milson 2008). Als die Hauptvertreter des Anti-Israelismus gelten junge gewaltbereite Migranten, weil sie wegen ihres arabischen und/ oder muslimischen Hintergrunds einer unkritischen Solidarität mit den Palästinensern und dem Einfluss islamistischer Propaganda unterliegen (s. Amadeu Antonio Stiftung 2009, FRA 2009: 23). Vgl. auch Küntzel (2007). 
„neben dem alten religiösen und rassischen Judenhaß ist ein neuer entstanden, der global operiert, der den 'Juden' nicht als 'vaterlandslosen Gesellen', sondern als Inkarnation Israels verdammt. Neu sind der mörderische Antisemitismus des radikalen Islamismus und die Bestätigung, die dieser Haß und die Selbstmordattentate unter manchen Intellektuellen erfahren, die bei klassisch rechtem Rassismus weniger duldsam wären“.

Auch Goldhagen (2004: 93 f., 97) betont diese Komponente als „globalisierten Antisemitismus“ (vgl. hierzu auch Kreis 2005: 23 sowie Wistrich 2005: 2, 2007 und 2010). Die starke Fixierung auf Israel als das vorherrschende Kennzeichen des aktuellen Antisemitismus veranlasst auch Rensmann, dieses Phänomen in die Kategorie des Antizionismus einzuordnen (Rensmann 2004: 87, s. hierzu auch Gessler 2004: 126). Als Anti-Israelismus oder Israelfeindschaft zeigt sich hier eine Kommunikationsform, mit der zwar vorgegeben wird, lediglich die israelische Politik zu kritisieren, die sich aber tatsächlich gegen das Existenzrecht Israels richtet (s. hierzu auch Klug 2004:227, der dies als „neuen Antisemitismus“ bezeichnet). Kritisiert wird Israel, gemeint ist aber der Staat als Symbol jüdischen Lebens. Diese Kommunikationsform ${ }^{61}$ ist gesellschaftlich als politisch korrekt akzeptiert und kann offen artikuliert werden (s. hierzu auch Schapira/Hafner 2006).

Für Vertreter der Kontinuitätsthese haben die aktuellen Ausprägungen des Antisemitismus aufgrund des Vorhandenseins tradierter Stereotype dagegen keine neue Qualität ${ }^{62}$ (vgl. Bergmann 2001: 38; s. aber Fußnote 60); aufgrund der hohen Adaptationsfähigkeit nimmt Antisemitismus aktuell auch die Form des Antizionismus oder der Israel-Kritik an (Benz 2004: 24, Bergmann ${ }^{32006: 117 f ., ~ s . ~}$ u. a. auch Quadfasel 2005: 188). Holz (2005) bezeichnet allgemein das Phänomen des veränderten Antisemitismus ab 1945 als „demokratischen Antisemitismus“, eine Judenfeindschaft, die in der demokratischen Öffentlichkeit geäußert werden kann und deren Kern die Vergangenheitsbewältigung durch Täter-Opfer-Umkehr ist (Holz 2005: 57, 59).$^{63}$ Für Holz stellen deshalb Antizionismus und Anti-Israelismus, wenn sie diesem Kern zuzuordnen sind, ebenfalls nur angepasste Varianten

61 Daher sehen auch Bergmann/Heitmeyer (2005a, b) als Konsequenz dieser Umwegkommunikation, dass sich das Sagbarkeitsfeld für Antisemitismus insbesondere in der Mitte der Gesellschaft vergrößern kann (was heute bereits als gegeben angesehen werden muss).

62 Dabei wird nicht berücksichtigt, dass tradierte Stereotype nicht nur einfach aus aktuellem Anlass reaktiviert werden, sondern auch konzeptuellen Verschiebungen und Elaborationen unterliegen können (s. Kap. 5).

63 Die Bezeichnung „demokratischer Antisemitismus“ ist irreführend, denn sie kann durch das positiv wertende Adjektiv demokratisch implizieren, dass dieser Antisemitismus eine auf Menschenrechten beruhende demokratische Mehrheitsentscheidung und ein harmloses Phänomen sei. 
des sogenannten sekundären Antisemitismus dar. Ähnlich wie Bergmann lehnt Holz für die aktuellen antisemitischen Äußerungsformen den Begriff des „,neuen Antisemitismus“ als Bezeichnung ab, weil dies bedeute, dass sich grundlegende Muster der Semantik änderten und daher ein neuer Typus des Antisemitismus entstehe (vgl. Holz 2005: 11). Holz sieht allerdings in der starken Fokussierung auf Israel in den verschiedensten politischen Strömungen und Bevölkerungsgruppen auch eine neue Qualität (vgl. Holz 2005: 111). Typisch für diesen ,,antizionistischen Antisemitismus“ sei die Unterscheidung zwischen ,jüdisch“ als religiöser und „zionistisch“ als politischer Bezeichnung, sodass nur Zionisten (ergo der Staat Israel) als politischer Feind gelten, aber nicht Juden als Kollektiv, Rasse oder Religion gemeint seien ${ }^{64}$ (vgl. Holz 2005: 43). Holz (2005: 97) betont zugleich, dass dieser antizionistische Antisemitismus in der demokratischen Öffentlichkeit zunehmend mehrheitsfähig werde (s. auch Müller 2006: 309). Damit wird auch von Vertretern der Kontinuitätsthese der Wandel im kommunikativen Umgang mit Antisemitismen gesehen, aber nicht als wesentliche Neuerung betrachtet.

$\mathrm{Zu}$ den kommunikativen Ereignissen, die vor allem den politischen Diskurs in Deutschland spezifisch geprägt und dahingehend verändert haben, dass das Feld des Sagbaren ausgeweitet wurde, gehören die Goldhagen-Debatte 1996, die Walser-Rede-Debatte 1998, die Bundestagsdebatte zum Holocaust-Mahnmal in Berlin 1999, die Debatte zur Entschädigung von NS-Zwangsarbeitern und die Rolle jüdischer Organisationen 2001 sowie die Möllemann-Friedman-Debatte und die Kontroverse um judenfeindliche Positionen in der FDP 2002 (s. hierzu Rensmann 2004: 60, 2006: 44 sowie Reinfrank/Ebbrecht 2004, Nonn 2008: 102 ff., Pallade 2008a, b, Reinfrank 2008). Diese öffentlich geführten Auseinandersetzungen haben dazu geführt, dass Tabuisierungsgrenzen verschoben wurden. Insbesondere die Friedenspreisrede von Martin Walser stellt eine Zäsur dar, weil sich hier antisemitische Abwehraggressionen gegen ein Erinnern an die NS-Verbrechen erstmals öffentlich entfalten und etablieren konnten, ohne dass es zu einer einheitlichen öffentlichen Sanktionierung kam: „Hier hatte eine intellektuelle moralische Instanz mit Pathos offen artikuliert, was bislang weitgehend im öffentlichen Raum der in der gesellschaftlichen Mitte angesiedelten Diskurse als tabuisiert oder zumindest inopportun galt“ (Pallade 2008a: $321 \mathrm{f}$.). Die neue Qualität seit der Walser-Rede-Debatte besteht darin, dass antisemitische Äußerungen immer weniger auf Widerspruch stoßen und als „normal“ angesehen werden, aber auch darin, dass Ideologeme der politischen Randgruppen verstärkt Eingang in die politische und gesellschaftliche Mitte gefunden haben (vgl. Reinfrank 2008: 109, Pallade 2008a: 340). Unangemessene und geschichts-

64 Wir werden zeigen, dass dies keineswegs der Fall ist (vgl. Kap. 7). Der auf Israel bezogene Antisemitismus weist alle Charakteristika der tradierten Judenfeindschaft auf. 
unsensible Verbalformen wie das Kompositum Antisemitismuskeule wurden zum salonfähigen Schlagwort. An diese veränderten kommunikativen Bedingungen konnte auch Jürgen W. Möllemann mit seinem rechtspopulistischen Wahlkampf 2002 anschließen; bei ihm tritt jedoch eine Kopplung von Erinnerungsabwehr und Antizionismus in den Mittelpunkt, bei der die Täter-Opfer-Umkehr hinsichtlich der nationalsozialistischen Vergangenheit mit der Konstruktion israelischer Täterschaft begründet wird (vgl. Holz 2005: 23).

Als wesentliche Motivationsquelle sowie als Katalysator für antisemitische Tendenzen werden in der Forschung auch der Ausbruch der Zweiten Intifada und die Eskalation des Nahostkonflikts ${ }^{65}$ gesehen (wobei auch die Dimension des internationalen Terrorismus seit dem 11. September 2001 eine Rolle spielt; vgl.

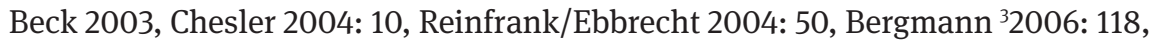
Müller 2006: 309, Reinfrank 2008: 110, Wetzel 2008: 88, FRA 2009: 24). So spricht Beck (2003) von der „Entgrenzung der Intifada“ und der „Globalisierung des israelisch-palästinensischen Konflikts“, weil sich die Israelfeindschaft vielerorts (lokal) und weltweit (global) in Aggression und Gewalt ${ }^{66}$ gegen jüdische Vertreter und Einrichtungen entlade und damit über die Grenzen des Nahen Ostens hinaus wirke.

Unabhängig von der Debatte, ob die aktuell zu beobachtenden Veränderungen nun als neu oder alt-neu, tradiert oder innovativ zu bewerten sind, lässt sich Folgendes konstatieren:

Israel steht als Hassobjekt im Mittelpunkt des aktuellen Antisemitismus. Der Nahostkonflikt bildet im 21. Jahrhundert den herausragenden Begründungszusammenhang für antisemitische Meinungsäußerungen und dient als Katalysator der Judenfeindschaft. Anti-Israelismus wird nicht nur von rechten oder linken Extremisten, sondern auch von Akademikern und Intellektuellen sowie Vertretern der Gesellschaftsmitte kommuniziert, da er als politisch korrekt ausgegeben werden kann. Diese Situation ist nicht regional begrenzt, sondern globalisiert,

65 Wenn sich beim Phänomen des Antisemitismus auch jedwede monokausalen Erklärungsmuster verbieten, so besteht heute kein Zweifel mehr, dass ein Zusammenhang zwischen der Zunahme des Antisemitismus in der Variante des Anti-Israelismus und der seit 2000 veränderten, zu Ungunsten Israels einseitigen, tendenziell extrem negativen und zum Teil hoch emotionalen Berichterstattung zum Nahostkonflikt in den Medien besteht (vgl. Behrens 2003, Jäger/Jäger 2003, Wistrich 2003, Schwarz-Friesel 2007 und 2012c, Schapira/Hafner 2010, Beyer 2012; vgl. hierzu auch Langenbucher/Yasin 2009). S. hierzu Kap. 7.3. 66 Ausschlaggebend sei hier nach Einschätzung des US-Sachverständigen Baker, dass dieser neue Antisemitismus den Staat Israel zu einem besonderen Ziel von nicht-traditionell rassistischen Gruppen mache, d. h. er wird nicht nur von den „üblichen“ Rechtsextremen vertreten, sondern vor allem von arabischen bzw. muslimischen Migranten (vgl. Baker 2006: 157). 
d. h. die Israelfeindschaft tritt weltweit auf und wird vor allem technisch über die Massenmedien verbreitet (vgl. Chesler 2004: 76-86, Reinfrank 2008: 107 f.).

Neu ist die Qualität der verbalen Gewalt im alltäglichen und öffentlichen Diskurs gegenüber Israel: Es sind zunehmend auch im Kommunikationsraum der Mitte brachiale Formen der Entwertung (z. B. NS-Vergleiche und drastische Hyperbeln) zu konstatieren (s. Kap. 7.2.2). Neu ist auch die Bereitschaft von immer mehr Menschen (weltweit), drastisch abwertenden und de-realisierenden Aussagen über den jüdischen Staat Israel zuzustimmen (s. hierzu z. B. den EUMCReport 2003 und 2004, die Ergebnisse der ADL-Umfrage aus dem Jahr 2009 und der Forsa-Umfrage 2012 (Weber 2012)). Neu ist zudem die unbeschränkte Zugänglichkeit und massive Verbreitung von Verbal-Antisemitismen (sowie judenfeindlichen Karikaturen) über das Internet, das als virtuelles Welt- und Kommunikationssystem längst wesentlicher Bestandteil der realen Welt geworden ist (s. Marx/ Schwarz-Friesel 2012) und maßgeblich dazu beiträgt, auch explizit judenfeindliche Äußerungen sowie anti-israelische Hassbotschaften schnell und effektiv an unzählige Rezipienten zu vermitteln. Dabei sind es keineswegs nur Internetseiten von Rechtsradikalen, Fundamentalisten oder Islamisten (s. hierzu Wetzel 2005), die antisemitisches Gedankengut kommunizieren, sondern auch Internetforen, Kommentarbereiche und soziale Netzwerkseiten der gesellschaftlichen Mitte (s. Schwarz-Friesel 2012a). Dadurch können Habitualisierungs- und Normalisierungseffekte für judenfeindliche Äußerungen im öffentlichen Kommunikationsraum entstehen und sich vertiefen.

Dass Antisemitismus in Deutschland ein aktuelles und keineswegs bloß historisch relevantes Phänomen ist, das nicht nur an den extremen Rändern der Gesellschaft, sondern trotz aller Aufklärungsarbeit auch fest verankert in Teilen der (gebildeten und nicht radikalen) Mitte existiert, wird allerdings außerhalb der Antisemitismusforschung noch immer zu wenig beachtet und $\mathrm{zu}$ wenig als problematisch bzw. besorgniserregend empfunden.

Auffällig ist auch die Diskrepanz zwischen den Empfindungen der Betroffenen (d. h. der jüdischen Gemeinden und Institutionen; vgl. z. B. Pallade 2008a, b) und den Beobachtungen sowie Analysen von Forschern (die sich weitgehend decken) einerseits und den Einschätzungen von großen Teilen der Bevölkerung andererseits:

\footnotetext{
„Während Juden von Antisemitismus betroffen sind und sich, wie etwa die nach wie vor notwendigen Sicherheitsmaßnahmen vor jüdischen Einrichtungen und Synagogen in Europa dokumentieren, als Minderheit zu Recht von gewaltbereiter Judenfeindschaft bedroht fühlen, sehen heute Teile der Mehrheitsgesellschaft eher unbegründete Antisemitismusvorwürfe als hervorstechendes gesellschaftliches Problem und Antisemitismus als ein Phänomen der (europäischen) Geschichte.“ (Rensmann/Schoeps 2008: 11)
} 
Trotz der jahrzehntelangen offiziellen Ablehnung und Ächtung von Antisemitismus, intensiver Aufklärungsarbeit und des Bemühens der Regierenden, antisemitischer Gewalt und Einstellung entgegenzutreten, sind große Teile der Bevölkerung keineswegs hinreichend sensibilisiert für die Gefahren von stereotypen Denkstrukturen und vorurteilsschaffender Feindbildrhetorik. Die Hemmschwelle, verbal-antisemitische Äußerungen auch in der Öffentlichkeit zu artikulieren, ist in den letzten Jahren deutlich gesunken (vgl. Schwarz-Friesel 2009a, b, 2010a, b und 2012a), die Bereitschaft, Aussagen mit stereotypen judeophoben und/oder anti-israelischen Inhalten zuzustimmen, dagegen gestiegen. Die These vom „kollektiven Lernprozess“ in Bezug auf Antisemitismus, die Bergmann (1997: 502) für Deutschland und für den demokratischen Diskurs konstatiert hat, kann angesichts der aktuellen Forschungsergebnisse so nicht mehr uneingeschränkt aufrechterhalten werden (s. hierzu auch Rensmann 2004: 490 ff., 224 ff. sowie Nonn 2008: 103).

Die Expertenkommission des Bundestages kommt in ihrem 2011 veröffentlichten Bericht entsprechend zu dem folgenden Schluss:

\begin{abstract}
„Der Bericht konnte zeigen, dass in der deutschen Mehrheitsgesellschaft in erheblichem Umfang antisemitische Einstellungen in unterschiedlichen inhaltlichen Ausprägungen vorhanden sind, die wiederum auf weitverbreiteten Vorurteilen und tief verwurzelten Klischees beziehungsweise auf schlichtem Unwissen über Juden und Judentum basieren. Angesichts moderner Kommunikationsformen, wie sie insbesondere im Internet bestehen, ist eine Verbreitung dieses Gedankenguts kaum zu unterbinden. Die weitgehende Tabuisierung des Antisemitismus im öffentlichen Diskurs, die bisher für die Bundesrepublik kennzeichnend war, droht damit, entscheidend an Wirksamkeit zu verlieren. Besonders gefährlich erscheint die Anschlussfähigkeit des bis weit in die gesellschaftliche Mitte reichenden und nicht hinreichend geächteten Antisemitismus für rechtsextremistisches Gedankengut. Nicht zuletzt angesichts der verheerenden historischen Auswirkungen des nationalsozialistischen Antisemitismus ist entschlossenen Gegenmaßnahmen eine hohe Priorität einzuräumen.“(BMI 2011: 182)
\end{abstract}

\title{
Fazit
}

Judenfeindseligkeit war und ist fester Bestandteil der abendländischen Denkund Sprachstrukturen. Jahrhunderte der Diffamierung und Stigmatisierung von Juden haben tiefe Spuren im kollektiven Gedächtnis und in den kommunikativen Sprachgebrauchsmustern hinterlassen. Der Blick auf die Geschichte zeigt nicht nur die lange Tradition judenfeindlichen Denkens und Fühlens; er zeigt auch bestimmte, kontinuierlich erhaltene und reproduzierte Muster der verbalen Stigmatisierung und Diffamierung auf, die semantisch-konzeptuelle Konstanten 
widerspiegeln: Das Stereotyp von den Juden als den FREMDEN, den ANDEREN, ist ein Kategorisierungs- und Entwertungskonzept, das über zwei Jahrtausende in diversen Abwandlungen erhalten geblieben ist. Je nach religiöser, ideologischer oder politischer Perspektive sind Juden fremd und anders, weil sie den Kritikern zufolge nicht den wahren Glauben vertreten oder weil sie eine eigene Rasse darstellen oder weil ihre Gesinnung feindselig, ihr Verhalten unanständig und destruktiv ist. Die im Laufe der Jahrhunderte zusätzlich entstandenen spezifischen Stereotype bilden zusammen und miteinander verknüpft ein kognitives System von Glaubensinhalten, welches das emotionale Ressentiment gegenüber Juden mental stützt. Die Sprache archiviert Komponenten des kollektiven Bewusstseins und macht sie über ihre bedeutungstragenden Formen transparent. Judenfeindliche Äußerungen transportieren und tradieren geistige Stereotype, welche die Basis antisemitischer Grundeinstellungen bilden. Sie tragen daher maßgeblich dazu bei, Denkschablonen und Klischees zu erhalten. So werden über Sprachgebrauchsmuster judenfeindliche Einstellungen aktiviert und reaktiviert. Entsprechend zeigen die Benennungen und Beschreibungen von Juden und Judentum eine ungebrochene Kontinuität judenfeindlicher Konzepte sowie Muster der mentalen Entwertung wie Dehumanisierung, Dämonisierung und De-Realisierung durch Phantasiekonstruktionen und Verschwörungstheorien.

Das nachfolgende Kapitel wird einerseits zeigen, welche tradierten mentalen Stereotype der Judenfeindschaft über die Epochen hinweg im kulturellen und kommunikativen Gedächtnis der Deutschen erhalten und bis zum heutigen Tag trotz aller Aufklärungsarbeit nach dem Holocaust artikuliert werden. Andererseits werden wir erklären, inwiefern kognitive Formen des Antisemitismus nicht nur in neuen Ausdrucksvarianten auftreten, sondern auch inwiefern alte judenfeindliche Konzeptualisierungen dabei aktuell modifiziert bzw. elaboriert werden. 